INCIDENCIA DE LA TRANSFERENCIA TECNOLOGICA EN LA PRODUCTIVIDAD DEL CACAO EN COLOMBIA EN LAS ZONAS DE SANTANDER, ARAUCA Y ANTIOQUIA.

Juan Carlos Fuentes Benítez ${ }^{1}$

UNIVERSIDAD SANTO TOMAS

FACULTAD DE ECONOMIA

MAESTRIA EN CIENCIAS ECONOMICAS

Bogotá., D.C. Colombia, Dic 2014

${ }^{1}$ Economista Universidad Santo Tomás Bogotá 


\title{
INCIDENCIA DE LA TRANSFERENCIA TECNOLOGICA EN LA PRODUCTIVIDAD DEL CACAO EN COLOMBIA EN LAS ZONAS DE SANTANDER. ARAUCA Y ANTIOQUIA
}

\author{
Juan Carlos Fuentes Benítez \\ Tesis presentada como requisito para obtener el título de: \\ Magister en Ciencias Económicas
}

Director:

Gustavo Adolfo Díaz Valencia*

UNIVERSIDAD SANTO TOMAS

FACULTAD DE ECONOMIA

MAESTRIA EN CIENCIAS ECONOMICAS

Bogotá., D.C. Colombia, Dic 2014

* Ph. D en economía. Docente Maestría en Ciencias Económicas Universidad Santo Tomás. Bogotá 


\section{CONTENIDO}

RESUMEN

1. INTRODUCCION

2. ASPECTOS CONCEPTUALES Y TEORICOS.

2.1 COSTOS DE PRODUCCION EN EL SECTOR AGROPECUARIO. 7

2.2. TRANSFERENCIA DE TECNOLOGIA PARA EL SECTOR AGROPECUARIO 11

2.2.1 La eficiencia tecnológica en el sector agropecuario 11

2.3 TRANSFERENCIA DE TECNOLOGIA PARA EL CACAO EN COLOMBIA 14

2.3.1 Factores climáticos que afectan el rendimiento del cacao 14

2.3.2. Temperatura 15

2.3.3. Precipitación 15

2.3.4 Radiación Solar Fotosintéticamente Activa. 16

2.3.5. Viento. 16

2.4 FACTORES FISIOLOGICOS DE LA PRODUCCION. 17

2.4.1 Tamaño y eficiencia del follaje. $\quad 17$

2.5. DESARROLLO VEGETAL. 18

2.5.1. Floración. 18

2.5.2. Fructificación. 19

2.6. MATERIAL GENETICO 20

2.6.1. Tipo Criollo o nativo 20

2.6.2. Tipo Forastero $\quad 21$

2.6.3 Tipo híbrido $\quad 21$

3. ASPECTOS TEORICOS 21

4. HECHOS ESTILIZADOS 27

5. METODOLOGIA Y MODELO DE ADOPCION DE IMPACTO 34

5.3 PRUEBAS DE SIGNIFICANCIA ESTADÍSTICA 42

6. CONCLUSIONES Y RECOMENDACIONES

REFERENCIAS BIBLIOGRAFICAS $\quad 46$ 


\section{RESUMEN}

La contribución al cambio técnico del sector agropecuario a nivel mundial ha estado determinado por el desarrollo de nuevas tecnologías que involucran procesos de Investigación, Desarrollo e Innovación; estos procesos tienen como principal objetivo incrementar la productividad agropecuaria mediante la transferencia de tecnología. Sin embargo, es el productor agropecuario quien decide adoptar o no adoptar esos nuevos desarrollos tecnológicos ya que puede incidir directa o indirectamente en los costos de producción aumentando o disminuyendo el nivel de ingresos. Para este estudio se seleccionó la cadena del cacao en Colombia como un producto agrícola priorizado en el Plan Nacional de Desarrollo Cacaotero 2012-2021, con el fin de evaluar los procesos de transferencia de tecnología y su relación con la productividad, donde se seleccionaron 21 fincas ubicadas en las zonas productoras de Santander, Arauca y Antioquia. Para tal fin se tomó como referencia las encuestas elaboradas por Fedecacao en el año 2013, siendo éste el año base del presente trabajo. Con los datos obtenidos se formuló un modelo de adopción e impacto que estime la probabilidad de aumentar la productividad cuando el productor adopta nuevas tecnologías, de esta manera se espera demostrar que los sistemas renovados de cacao tienen una probabilidad muy alta de adoptar tecnologías frente a un cultivo de sistema tradicional.

PALABRA CLAVE: Transferencia de tecnología, costos de producción, cadena de cacao, Adopción de impacto 


\section{INTRODUCCION}

Los resultados en investigación agropecuaria deben propender a generar impactos socioeconómicos, ambientales, políticos e institucionales que contribuyan al desarrollo de la agricultura, el cual debe tener un enfoque sistémico que involucre una evaluación multidimensional en su sistema de producción, es por esta razón que los economistas jugamos un papel relevante con relación a los estudios de adopción e impacto de las tecnología desarrolladas por los centros de investigación y de esta forma poder tomar decisiones que contribuyan al cambio técnico del sector agropecuario generando productividad, competitividad y sostenibilidad.

A nivel mundial los centros de investigación agropecuaria están encaminados a generar procesos de Investigación, desarrollo e innovación que sirvan para diseñar políticas de desarrollo agropecuario. Sin embargo, son los productores quienes toman la decisión de adoptar nuevas tecnologías siempre y cuando contribuya a obtener mejores rendimientos.

De acuerdo al último boletín de estadísticas del cacao publicado en marzo de 2014 por la organización mundial de Cacao ICCO, la producción de cacao ascenderá a 4.195.000 toneladas siendo los principales productores: África con 3.100 .000 toneladas, Asia y Oceanía con 559.000 toneladas y América con 536.000 toneladas

En Colombia existe un interés por impulsar el cultivo del cacao de acuerdo al Plan Nacional de Desarrollo Cacaotero 2012- 2019; el cual busca potencializar un conjunto de acciones sobre la política sectorial, acompañamiento al productor, investigación y comercialización; este plan debe responder a las necesidades del productor en cuanto a la asistencia técnica y transferencia de tecnología y generar excedentes económicos. 
Como parte del análisis de este trabajo se tuvieron en cuenta las condiciones agronómicas del cultivo del cacao, así como también la estructura de costos obtenidos por medio de encuestas realizadas a 21 fincas de pequeños y medianos productores en las zonas de Santander, Arauca y Antioquia en el año 2013 información que fue suministrada por Fedecacao.

Sin embargo, esta sin resolver el problema de la productividad $y$ competitividad de esta cadena. El problema se plantea en el sentido de que los altos costos de producción no favorecen la competitividad del cultivo dado que los procesos de transferencia de tecnología no llegan a todos los productores.

Aunado a esto una las debilidades del sector agropecuario colombiano es la carencia un sistema estructurado de costos de producción y la baja posibilidad de consulta de manera abierta, oportuna y confiable para poder evaluar los procesos de transferencia de tecnología Esta situación afecta a una gran parte de las cadenas agro productivas y se caracteriza por factores tales como: dispersión e información desactualizada; escasa coherencia y representatividad de los datos de costos; limitada posibilidad de realizar análisis y estimaciones con bajos márgenes de error, todo lo cual dificulta la toma de decisiones de política principalmente en aspectos de competitividad, crédito, precios y tecnología.

El Cultivo del cacao es una alternativa que puede generar excedentes económicos especialmente para el pequeño y mediano productor. Se necesita entre otras, mejorar la calidad del grano a través de sistemas de producción renovados que involucren estrategias tecnológicas para fortalecer la cacaocultura en Colombia mediante genotipos de cacao que sean resistentes a enfermedades, calidad y mayores rendimientos.

Dado los referentes anteriores el objetivo de este trabajo es evaluar el nivel de adopción de procesos de transferencia de tecnología y su contribución a mejorar la productividad del cacao en Colombia en las regiones productoras de Santander, Arauca y Antioquia. Para validar este objetivo se desarrolló la 
metodología de adopción e impacto mediante la estimación de un modelo de probabilidad con variable dicotómica dependiente, esta metodología esta soportada con el marco teórico de excedentes económicos de la teoría Marshaliana, enfoque que permite que se estime el beneficio económico generado por la adopción de innovaciones tecnológicas.

Para obtener los resultados de la investigación se tabularon las encuestas suministradas por parte del gremio a 21 fincas representativas de las zonas productoras de Santander, Arauca y Antioquia, donde se construyó una matriz con información de los sistemas de cultivo renovado y tradicional de cacao y las diferentes variables como insumos maquinaria y asistencia técnica, así como también el género y la tenencia de la tierra. Los datos fueron modelados por el software estadístico Stata 13.0 en donde se obtuvo información con variables dicotómicas de selección discreta y se estimó un modelo PROBIT que permitió normalizar la muestra.

\section{ASPECTOS CONCEPTUALES Y TEORICOS.}

Con el fin de identificar y analizar los principales procesos de transferencia de tecnología se desglosara los aspectos conceptuales que permitirán fundamentar el objetivo de la investigación, para ello se analizaran los siguientes conceptos: Costos de producción, transferencia de tecnología y condiciones agronómicas para el cacao.

\subsection{COSTOS DE PRODUCCION EN EL SECTOR AGROPECUARIO.}

De acuerdo al documento de estrategias metodológicas para la recolección y estructuración de costos de producción, elaborado por Corpoica, año 2014, la estructura de los costos de producción en el sector agropecuario depende del nivel tecnológico de las plantaciones y su localización dada la hetereogeidad de nuestro país. Los costos en que incurre la producción de cacao están determinada por los costos de mano de obra que representan alrededor del $55 \%$ de los costos totales, 
con excepción del primer año. Durante este periodo se emplean más recursos en la compra de insumos.

Durante el primer año, la mano de obra se emplea en el establecimiento del cultivo en donde se realizan labores como preparación del terreno, construcción de drenajes, ahoyado y siembra de cacao y de los sombríos, transporte del material vegetal.

La labor que más peso tiene dentro de los costos de establecimiento es el ahoyado y preparación del terreno, durante el primer año también se realizan algunas labores de mantenimiento que tiene un peso del $28 \%$ dentro de los costos de la mano de obra.

Durante el segundo año las labores se orientan al mantenimiento del cultivo, principalmente lo relacionado con desyerbas y control fitosanitario actividad que participa con el $74 \%$ de los costos de mano de obra.

El cacao comienza a producir a partir del tercer año para plántulas hibridas y clones a partir del quinto año, por tal razón el cultivo del cacao debe estar acompañado de un cultivo transitorio que permita generar ingresos en el corto plazo.

La producción de cacao va aumentando paulatinamente hasta llegar a un pico de producción alrededor de los 7 a 11 años dependiendo de la variedad, en la medida en que va aumentando la producción de cacao, el peso de las labores de mantenimiento es cada vez menor y se aumentan los jornales destinados a cosecha y beneficio del grano.

El segundo rubro más importante dentro de los costos totales de producción son los insumos estos incluyen fertilizantes orgánicos y químicos, fungicidas, herbicidas, empaques y a partir del segundo año cerca del $95 \%$ de los costos de los insumos corresponden a correctivos del suelo.

La inversión en infraestructura y herramientas tiene una participación promedio del $4 \%$ de los costos totales, durante el primer año se debe invertir en tijeras, navajas 
y machetes, para la siembra y las podas de formación, a partir del tercer año inicia la producción de cacao y se requiere invertir en el beneficiadero que participa con el $28 \%$ de los costos en infraestructura y herramientas

Los costos de producción del cacao se calculan teniendo en cuenta que es un cultivo a largo plazo que requiere varios años para su establecimiento y que su cosecha se inicia de forma gradual hasta alcanzar su plena capacidad de producción. La duración del periodo de establecimiento y de cosecha dependerá del tipo de semilla y la asistencia técnica que se preste durante este periodo.

En las plantaciones hechas con semillas común, la producción inicia entre cuatro y cinco años después de sembrados y alcanzan su madurez fisiológica después de completar diez años de edad; en este momento es cuando el cultivador comienza a obtener la cosecha que el material es capaz de producir según sea su variedad.

Existe avances en cuando al cultivo de la semilla hibrida en el cual el tiempo de establecimiento y el de rendimiento por unidad de superficie se han modificado notoriamente, los arboles de cacao provenientes de semillas hibridas inician su fructificación a los dos años de sembrados en el campo y alcanzan su máxima producción a la edad de ocho años.

Con los sistemas de siembra tradicional, la etapa de producción económica se prolonga hasta los 40 años promedio, siendo mayor o menor según los cuidados del manejo que reciba la plantación.

Debido a esta condición de largo plazo del cultivo del cacao, hay que distinguir en el dos tipos de costos, a diferencia de los cultivos semestrales, anuales. Tales tipos de costos son: el de establecimiento y el de producción.

En términos generales, se entiende por costo del establecimiento el total de inversiones necesarias hasta que el árbol del cacao alcanza su máxima capacidad de producción. Su valor anual es muy variable debido a la naturaleza de las labores que se deben ejecutar y a los insumos que se deben utilizar en esta etapa. 
La duración de este periodo de establecimiento hasta la máxima capacidad de producción es de ocho años para los arboles procedentes de semillas hibrida y de diez años para los árboles que provienen de la semilla común no mejorada ni seleccionada. Sin embargo a partir del quinto año no solo se inicia la producción, sino que se normalizan los costos de mantenimiento.

Por la razón anterior, desde el punto de vista de préstamos bancarios el periodo de establecimiento se reduce a los cinco primeros años de vida del cultivo.

El costo de producción abarca el resto de tiempo y su valor anual es más o menos constante, debido a que las operaciones de manejo sufren muy pocas alteraciones.

El cálculo de los costos del establecimiento de un cultivo de cacao varía de una región a otra.

Hay que tener en cuenta los costos de mano de obra que en Colombia varían ampliamente de un sector a otro; la destreza del personal en el manejo de la finca, así como el grado de mecanización en labores de desyerbas, cosecha, secado del grano y otros factores influyen grandemente en los costos y en los desembolsos parciales.

Las facilidades del transporte que tengan una región pueden alterar los precios de los productos agroquímicos y las condiciones de fertilidad del suelo influyen en el tiempo requerido por el árbol para entrar en producción y en la cantidad de nutrimentos que es necesario agregar para obtener buenas cosechas; así mismo, la duración relativa de la estación seca o del periodo de lluvias influye en los costos, ya que crea la necesidad de riego o la ejecución de un mayor número de desyerba 


\subsection{TRANSFERENCIA DE TECNOLOGIA PARA EL SECTOR AGROPECUARIO}

La tecnología se ha convertido en el principal determinante del desarrollo económico y social de las naciones, no solo por ser la fuente primordial para aumentar la productividad de todas las actividades económicas, sino porque la misma afecta también al conjunto de la organización productiva y origina cambios en la estructura social.

La adopción de una tecnología por parte del productor agropecuario o agroindustrial constituye un proceso en donde actúan diversos factores que afectan tanto el grado (uso integral o parcial de la tecnología o sistema) como la tasa de adopción (uso total o parcial de la superficie cultivada potencial en el caso de los productores rurales) además, de un año a otro pueden cambiar ciertos factores, y favorecer u obstaculizar la adopción de determinada innovación.

Es importante identificar que el proceso de adopción difiere de una región a otra tanto dentro de un país, como en la región vecina o agroecológica donde se espera que la tecnología sea adoptada, se debe usar información sobre el proceso de adopción de tecnologías similares en las mismas regiones.

\subsubsection{La eficiencia tecnológica en el sector agropecuario}

En el estudio de FONTAGRO (2002), la eficiencia tecnológica se refiere al aporte de la tecnología para reducir la dependencia del uso de insumos, sean tecnológicos o naturales.

Principales indicadores de la eficiencia tecnológica de acuerdo al estudio de FONTAGRO (2002)

- “Uso de agroquímicos: está definido por los pesticidas, evaluado con base en la alteración( debido a la aplicación de tecnología) en la frecuencia, variedad de ingredientes activos y toxicidad de los productos; y por el uso de fertilizantes, evaluado con base en la alteración de la cantidad de 
abonos hidrosolubles, encalado, y micronutrientes aplicados como consecuencia de la tecnología."

- “Uso de energía: La energía es esencial en todas las etapas de la producción agropecuaria y abarca desde fuentes naturales, como energía solar e hidráulica, pasando por la energía agregada en los insumos, como fertilizantes, hasta el consumo más evidente de combustibles empleados en las operaciones mecanizadas"

- "Uso de recursos naturales: Además del uso de los insumos tecnológicos, la producción agropecuaria depende del uso de recursos naturales, considerados no simplemente como base para el sustento de las actividades productivas, lo cual se evalúa en el marco de la conservación ambiental, sino como recursos incorporados al proceso productivo, tales como insumos, cuyo uso es posible de cambiar según el nivel de eficiencia tecnológica. En ese indicador se evalúa por lo tanto, la necesidad impuesta por la tecnología del uso de agua para riego agua para procesamiento y suelo para siembra."

- “Recursos genéticos: la adecuada utilización de genotipos seleccionados por atributos de interés (resistencia de enfermedades, calidad sensorial y fisicoquímica"( FONTAGRO 2002; pág. 106 a 129)

El avance tecnológico juega un papel destacado en el desarrollo agrícola a través de la utilización de sistemas tecnológicos más adecuados y compatibles con las características agras productivas que generan cambios estructurales en el crecimiento del sector agrícola.

Según el estudio Métodos de evaluación y priorización en investigación agropecuaria (Kaimowitz; Et al 2012.), la transferencia de tecnología agrícola se define como todo proceso de investigación, desarrollo e innovación que induce al uso de semillas mejoradas, uso eficiente de bienes de capital en la producción de alimentos como un medio de incrementar la oferta de alimentos a los consumidores urbanos sin aumentar los precios con el fin de responder a la tendencia de una agricultura cada vez más globalizada y abierta al comercio 
internacional; esto conlleva implica mejorar procesos de productividad y competitividad.

En un estudio sobre la evaluación multidimensional de los impactos en la investigación agropecuaria (Días, A. Et al 2012). Se introduce los diferentes impactos de la evaluación multidimensional en la investigación agropecuaria que deberían tenerse en cuenta para el uso de tecnologías agropecuarias y están relacionadas con:

- "Dimensión económica: incremento de productividad, reducción de costos, expansión de producción en nuevas áreas maneja excedentes económicos basados en la elasticidad precio de la demanda y elasticidad precio de la oferta a partir de adopción de tecnología, ex ante, ex cursus, ex post, la rentabilidad de la inversión tasa interna de retorno (TIR) - Relación Costo -Beneficio, Valor actual neto (VAN)."

- "Dimensión ambiental: Se basa en tres componentes 1 eficiencia tecnológica: contribución de la tecnología para reducir la dependencia del uso de insumos tecnológicos, uso de agroquímicos, uso de energía y uso de recursos naturales , 2 conservación ambiental: los efectos de la tecnología en la calidad de los componentes del ambiente, atmosfera, capacidad productiva del suelo, agua y biodiversidad.3 recuperación ambiental basada en la conservación y sostenibilidad de los recursos naturales."

- "Dimensión social: en el contexto del empleo, empleo agrícola y no agrícola, el componente nutrición: corresponden a los cambios sobre el nivel o calidad de la nutrición de la población objetivo como resultado del uso del resultado del proyecto, el componente salud como resultado del acceso a agua potable, expectativa de vida, salubridad como resultado de la adopción de tecnologías en el proyecto, impacto Capital social: cambios en la habilidad de la población objetivo de conseguir objetivos comunes a través de la construcción de redes de apoyo y comunicación" 
- “Dimensión política- institucional: fortalecer redes de cooperación como centros de investigación públicos y privados, empresas, gobierno, ONG". (Días, A. Et al 2012, pág. 76 al 86).

\subsection{TRANSFERENCIA DE TECNOLOGIA PARA EL CACAO EN COLOMBIA}

\subsubsection{Factores climáticos que afectan el rendimiento del cacao}

Para entender los aspectos climáticos relacionados con el cultivo del cacao, es importante conocer lo referente al origen y distribución de la especie en el mundo. Como se sabe, el centro de origen del cultivo es la zona donde existan mayores variabilidades genéticas en plantas nativas no cultivadas. En la década de los cuarentas, Pound, citado por Wood y Lass (1985) encontró en América tropical y más propiamente en el triángulo formado por los ríos Caquetá, Putumayo y Napo (Valle del Amazonas), la zona más heterogénea en cuanto a especies y la mayor variación de tipos y razas de Theobroma. Para confirmar el descubrimiento en cuanto a la característica nativa y no adaptada de las plantas encontradas, se apoyó en la teoría que los indios amazónicos no bebían chocolate como los mayas y por tanto al no haber esta costumbre, era casi imposible que se hubiesen llevado semillas de otra zona. Según Duke (1983), se ha planteado una teoría sobre la distribución de la especie, la cual supuestamente se realizó gracias a la dispersión a través de los Andes y el Orinoco hacia el norte del continente y a través de la selva hacia el sur oriente del mismo.

Con el fin de integrar lo anterior con las características ecofisiológicas de la

especie, a continuación se describen los principales aspectos que afectan el crecimiento, diferenciación y producción de cacao con énfasis en las condiciones del agro colombiano. 


\subsubsection{Temperatura}

Afecta todos los procesos fisiológicos de las plantas, para el caso de Th. cacao, se ha determinado como óptimo el rango entre los 22 y $27^{\circ} \mathrm{C}$, una mínima de $15^{\circ} \mathrm{C}$ y una mínima absoluta de $10^{\circ} \mathrm{C}$. En el mundo se siembra cacao en zonas que oscilan entre los 19 y los $28^{\circ} \mathrm{C}$ de temperatura promedio diurna. El efecto de las temperaturas bajas se evidencia con los bajos crecimientos vegetativos, el mayor tiempo para que el cultivo inicie la producción, periodos largos en el crecimiento y maduración de frutos y en ocasiones bajos porcentajes de cuajamiento.

\subsubsection{Precipitación}

La precipitación, afecta el crecimiento, la diferenciación floral, la brotación y el cuajado de frutos. El cacao biológicamente es una especie frutícola, pues los órganos aprovechables hacen parte de los ovarios maduros y fertilizados.

Los cultivos de cacao se desarrollan y crecen con éxito en zonas con precipitación entre los 1800 y los $2000 \mathrm{~mm}$ anuales de lluvia. No obstante, la cantidad de agua en forma de precipitación será función de la distribución de la misma en el año y de intensidad de las lluvias. Los frutales necesitan de periodos secos estresantes para desarrollar la evocación floral, seguidos de periodos lluviosos inductores de la brotación reproductiva. La planta de cacao es poco tolerante a la sequía. Al comparar la hojas de cacao con las del café, las del primer cultivo cuando pierden del 17 al $25 \%$ de agua, mientras que las del segundo lo hacen al perder el $57 \%$.Una pérdida de agua en la hoja de cacao equivalente al $3.3 \%$ de la hoja, o perder el 55 de agua de la misma, ocasiona el cierre total de los estomas, eso equivalentes a decir que el fenómeno es similar a cuando se retira totalmente una hoja de la rama, pues en esta condición los estomas se cierran totalmente entre 5 y 6 minutos (Manfred, 1998; Alvim, 1975). 
Existen zonas en Colombia con regímenes unimodales de lluvia como la Costa Pacífica, los Llanos Orientales y algunas partes de la Amazonia, en donde las cosechas son muy marcadas y estacionales, precisamente por no contar sino con un solo periodo de estrés. En otras zonas como el eje cafetero y los valles interandinos, los regímenes bimodales permiten dos cosechas marcadas en el año y dos épocas muy bajas de producción, sin que ésta llegue a cero. Precisamente, en estas zonas siempre se encontrará mazorcas ya sea en alta o baja proporción, en los árboles, un aspecto beneficioso para el flujo de caja, pero perjudicial a la hora del manejo fitosanitario.

\subsubsection{Radiación Solar Fotosintéticamente Activa.}

Se entiende por radiación solar Fotosintéticamente activa, la cantidad total de energía proveniente del sol en forma de fotones y con longitudes de onda entre los 400 y los 700 nanómetros $(\mathrm{nm})$. Ha sido establecida como uno de los factores determinantes para estimar el rendimiento potencial de los cultivos ya sean densos o sembrados en arreglos especiales (De Castro and Fetcher, 1998).

\subsubsection{Viento.}

Dos aspectos se estudian relacionados con el efecto del viento en las plantaciones de cacao: la deshidratación que causa sobre las hojas y los daños mecánicos en la estructura de la planta. En cuanto al primer caso, se ha establecido que un cultivo sin barreras cortaviento o sin sombra de estratos altos forestales, puede ser severamente afectado por acción de la velocidad del viento, hasta llegar a la defoliación total al cabo de ocho meses de soportar estas corrientes. Se reportan datos de 2,5 m.s $\mathrm{s}^{-1}$ como velocidad máxima permisible para no causar cierre estomático y secamiento en la lámina foliar (Alvim, 1987; Leite et al ., 1979). Es claro que el viento no solo incrementa las tasas transpiratorias en las hojas, sino que remueve con tal fuerza la capa de frontera foliar lo cual disminuye la concentración de $\mathrm{CO}_{2}$ circundante y posiblemente la enzima Rubisco comience a 
tomar la alternativa como oxigenasa, aspecto que implica disminución de la tasa fotosintética neta.

\subsection{FACTORES FISIOLOGICOS DE LA PRODUCCION.}

\subsubsection{Tamaño y eficiencia del follaje.}

El índice de área foliar se expresa como la relación de la superficie de las hojas sobre la unidad de superficie del suelo y fisiológicamente representa el potencial fotosintético total de una planta o conjunto de ellas. En otras palabras, hace referencia al tamaño y capacidad de las demandas fotosintéticas para cubrir eficientemente la asignación y distribución de los fotoasimilados por unidad de área.

El cacao en el mundo se desarrolla en zonas con pequeñas variaciones climáticas durante el año, pese a lo anterior los árboles no crecen continuamente sino más bien, se comportan como plantas de crecimiento intermitente mostrando periodos definidos, según la localidad, de intensa renovación del follaje, seguidos de periodos de reposo vegetativo ( Wood y Lass, 1985).

Los flujos de crecimiento del follaje están relacionados con la caída de las hojas senescentes. En nuestro medio, una plantación renueva completamente el follaje entre 12 y 18 meses. En general el crecimiento de órganos vegetativos precede una intensa caída de hojas, por lo que se pude deducir que existe un punto alto de translocación de fotoasimilados del dosel a los órganos de almacenamiento, especialmente tallos y meristemos, para que luego esta energía sea útil para la inducción floral y las nuevas emisiones de hojas. Existen hipótesis para explicar la sincronización entre caída de hojas y flujos foliares:

La concentración de un inhibidor en las yemas vegetativas, producido por las hojas, se reduce debido a la caída de las mismas, y esto desencadena una 
regulación hormonal para inducir ablandamiento de paredes celulares, división celular y diferenciación (Asesten and Zavada, 2001)

Un reloj biológico interno hace que por inducción climática, las láminas foliares descarguen los fotoasimilados en los tallos y raíces, a su vez esto incrementará los niveles de ácido abcísico en los pulvinos y posteriormente con la síntesis de etileno se inicie el proceso de caducidad foliar (Aneja and Gianfagna, 1999).

Estudios realizados por Gastal and Lemaire (2002), asignan mucha importancia a la humedad del suelo y del aire respecto a la brotación y renovación de follaje en Th. cacao. Se ha encontrado que es necesario un prolongado periodo de carencia de agua para la iniciación de los flujos foliares, y a su vez, la presencia de lluvias después de la brotación es necesaria para el crecimiento de las hojas recién formadas. Es evidente que el ciclo completo de la brotación foliar está siempre asociado con lluvias después de un periodo de falta o deficiencia de agua (Alvim and Alvim, 1976). Esto indica que el crecimiento del cacao es hidroperiódico, tal y como sucede con otras plantas cuyos órganos de aprovechamiento son los frutos.

\subsection{DESARROLLO VEGETAL.}

\subsubsection{Floración.}

La cantidad de flores de un árbol de cacao o un cultivo, varía significativamente de acuerdo al origen genético, edad de los árboles, factores edáficos y factores climáticos, especialmente la distribución y la cantidad de lluvias, la luz incidente y los promedios de temperatura.

De forma similar a la brotación de hojas, la floración se intensifica después de romper el estrés hídrico. Un periodo marcado de sequía o de poca cantidad de lluvia, hace que la planta evoque la diferenciación floral mediante una serie de acomodaciones hormonales y enzimáticas internas, de naturaleza bioquímica y 
donde una posible fitoregulador llamado florigen inicia los meristemos a la diferenciación (Taiz and Zeiger, 1998; Aneja y Gianfagna, 1999). Si este periodo de sequía es seguido de una época lluviosa, las plantas hidratan sus tejidos, la división celular en los meristemos se incrementa y finalmente se da como resultado la brotación reproductiva o floración (Alvim, 1975).

Duke (1983) afirma que la temperatura también influye en las épocas de máxima floración. Con promedios mensuales menores de $20^{\circ} \mathrm{C}$., la diferenciación floral se disminuye, lo que determina en algunas zonas patrones de cosecha muy definidos. Por el contrario, temperaturas medias superiores a $26^{\circ} \mathrm{c}$, provocan constantes floraciones en la planta y por tanto durante el año siempre se estará cosechando mazorcas. La distribución de fotoasimilados en los órganos demanda también es un factor decisivo en las floraciones efectivas del cacao. Las épocas de mayor carga de frutos coinciden con baja carga floral o con altos niveles de abortos de dichas estructuras, confirmando la hipótesis de la competencia de las demandas (Venkateswarlu and Visperas, 1989). Por el contrario, cuando existe baja carga de mazorcas, las floraciones son muy altas, bajo el aborto floral y por tanto ciclos continuos de producción. Se debe recordar que la planta de cacao fija su floración en zonas muy definidas denominadas cojines y que en estos lugares siempre se tendrá producción de frutos, caso muy diferente a otras plantas como el café o los cítricos, donde la producción siempre se localiza en zonas nuevas y de reciente crecimiento vegetativo.

\subsubsection{Fructificación.}

Está ligada con el crecimiento vegetativo al existir competencia interna por fotoasimilados, entre los frutos en crecimiento y las nuevas emisiones de brotes vegetativos. Como los tres procesos, crecimiento vegetativo, floración y crecimiento de frutos, están superpuestos, es claro que la planta deba ser muy eficiente a la hora de asignar y distribuir la materia seca. 
Según Hasenstein and Zavada (2001), debido a la acción de las auxinas (fitohormonas que actúan como reguladoras del crecimiento vegetal), la dominancia apical está determinando una mayor translocación de azúcares a los meristemos nuevos, más aún si las zonas o estratos bajeros de follaje tiene déficit de hojas fotosintéticamente activas. Esto dará como resultado el secamiento de los pepinos formados por simple acomodación biológica de la planta, pues la fuerza de la demanda excede en gran medida la capacidad y el tamaño de las fuentes para llenarla.

Una hoja de cacao produce entre 10 y $20 \mathrm{mg}$ de carbohidratos por día, lo que equivale de 70 a $140 \mathrm{mg}$ por semana. Esta producción varía con las condiciones del clima y el estado nutricional de los suelos, pero los datos se pueden adaptar a condiciones promedio universales. La duración del periodo de crecimiento de un

fruto es de 5, 5 meses y al final de este estado alcanza los $115.5 \mathrm{gr}$ de materia seca lo cual indica que se necesitarán entre 50 y 100 hojas para abastecer el llenado de una mazorca de manera óptima (Machado y Harwick, 1987).

\subsection{MATERIAL GENETICO}

En la actualidad el cultivo presenta tres grupos genéticos que a la vez determinan tres clases de grano (Pinzón y Ardila, 2005):

\subsubsection{Tipo Criollo o nativo}

Cacao genuino muy rugoso, con diez surcos profundos y cáscara delgada fácil de quebrar, reconocido como de gran calidad, de escaso contenido en tanino y reservado para la fabricación de chocolates más finos y de exquisito aroma. Los criollos puros presentan condiciones desfavorables para su manejo pues resultan muy delicados, con alta susceptibilidad a plagas y enfermedades y presentan poco rendimiento; dentro de estos se clasifican los originarios de México, Centroamérica y los venezolanos. En Colombia se encuentran pocas poblaciones de este tipo de cacao. 


\subsubsection{Tipo Forastero}

Originario de alta amazonia, son llamados amazónicos, tienden a ser amelonados, su cascara es lisa y gruesa con poca rugosidad y surcos poco profundos. Es el tipo de cacao más cultivado y de menor calidad en relación con el sabor y el aroma que confieren los granos al chocolate elaborado con ellos, pero tiene mejor rendimiento en contenido de grasas entre otras características. Se producen en Trinidad, Ecuador, África, Asia y Brasil.

\subsubsection{Tipo híbrido}

Entre los que se destaca el Trinitario, (originario de Trinidad) es un cruce sexual entre el Criollo y el Forastero, su calidad es más próximo al Forastero. Sin embargo, presenta la robustez de éste y el delicado sabor del cacao Criollo. Muchos clones conocidos en la actualidad como Universal, fueron seleccionados en Trinidad a partir de poblaciones híbridas, es decir, corresponden a individuos sobresalientes de la descendencia de aquellos cruzamientos. Actualmente se cultiva en Colombia y presentan resistencia a algunas enfermedades fungosas entre ellas Escoba de bruja causada por Crinipellis perniciosa (Pinzón y Ardila, 2005).

\section{ASPECTOS TEORICOS}

El estudio está basado en la teoría Marshalliana de excedentes económicos, el cual permite analizar el beneficio económico generado por la adopción de innovaciones tecnológicas.

El análisis de excedentes económicos busca generar una evaluación de adopción bajo el mejor escenario, lo que estaría dado por los productos agrícolas que generaran mayores excedentes económicos a la región o al país. Para realizar dicho análisis, se deben considerar los dos tipos de agentes que se encuentran en 
un mercado sin intervención estatal, consumidores y productores. En un principio se parte de una situación de equilibrio en la que dichos agentes consumen y producen la misma cantidad, esto significa que no hay ni escases ni abundancia de productos, y se vende a un precio determinado, que estará dado por $P_{0} y Q_{0}$. (Ver figura 1).

Los excedentes serán entonces el área bajo la curva de la demanda, para el caso del consumidor, y por encima de la curva de oferta, para el productor. En el caso particular del sector agropecuario, la nueva situación generada es aquella en la cual existe un grado de adopción, de un programa o de nuevas tecnologías, por tal razón se calculan de nuevo los excedentes y se procede a realizar la priorización, ordenando los resultados y escogiendo los proyectos o productos que generan un mayor nivel de excedente.

Figura 1. Excedentes económicos, situación inicial y final

Situación inicial

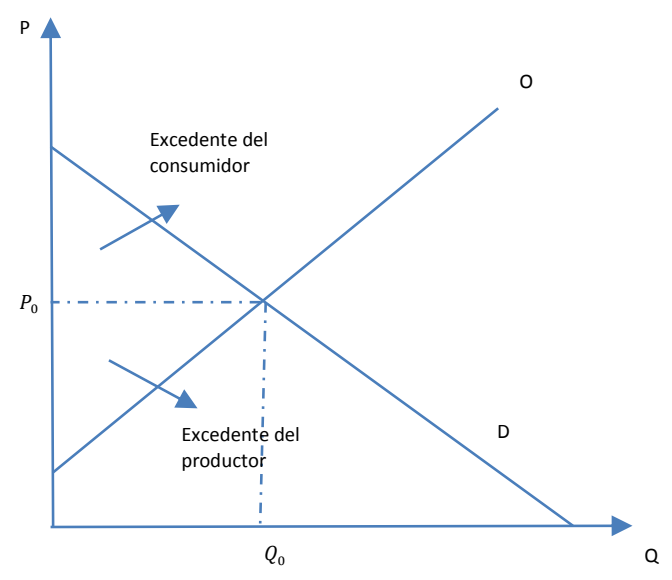

Situación final

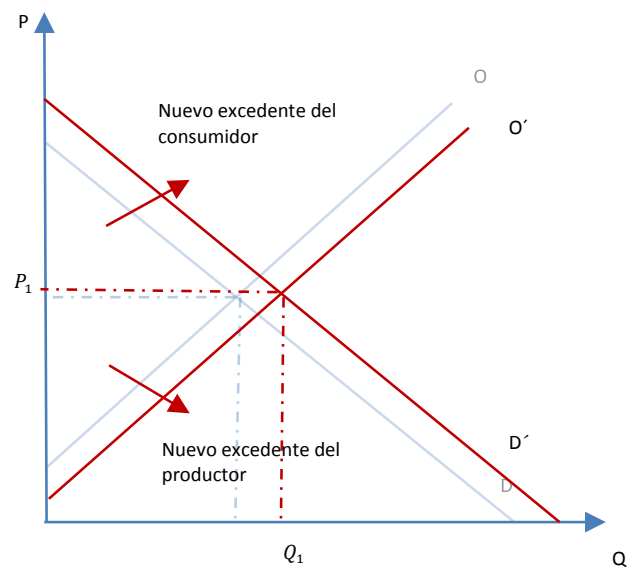

Fuente: elaboración propia

Dentro de las extensiones realizadas al modelo original de excedentes con convergencia del análisis de costo-beneficio, se encuentra Ramalho de Castro y Schuh (1974), quienes definieron una demanda y una oferta lineal y desplazaron esta última paralelamente para discutir los efectos de los cambios tecnológicos y de política económica sobre los costos y beneficios en la investigación 
agropecuaria. Norton, et al (1987) extienden el modelo donde el autoconsumo de los pequeños productores es importante y expanden simultáneamente la demanda y la oferta, aunque no contemplan curvas lineales para esta última.

Mientras Ramalho de Castro y Schuh realizaban estas extensiones al modelo, Araji, et al (1978), desarrollaron un modelo de excedentes económicos implícitos, en el que la oferta económica es inelástica (vertical) y la demanda es totalmente elástica (horizontal), agregando un cambio en la determinación de los beneficios a que estos autores calculan un flujo de beneficios y costos brutos para calcular el VPN, la TIR y B/C. Un importante resultado de estos análisis fue que la sensibilidad de los ratios costos-beneficios, los rendimientos esperados, los precios y la longitud de los rezagos entre los gastos de investigación y la disponibilidad de los resultados proporcionaron información a los tomadores de decisiones sobre la importancia relativa de las variables involucradas en la evaluación (Norton y Davis, 1980).

El estudio expuesto por Schultz en 1953, se calculó el valor de los insumos que se ahorraban en la producción al utilizar técnicas más eficientes y los comparo contra el costo de investigación y desarrollo y estimo los retornos a la investigación agrícola en un nivel agregado. Luego Grilliches (1958) calculó la perdida en el excedente social neto que pudo ocurrir si el maíz hibrido hubiese desaparecido, sus resultados muestran que la adopción de este tipo de maíz cambió la curva de oferta hacia abajo y a la derecha, por lo que pudo darse cuenta que la oferta es perfectamente inelástica, mientras la demanda tiene una elasticidad menor a uno.

En Colombia, Scobie y Posada (1978) hacen un análisis sobre el impacto del cambio técnico en la producción de arroz en dos clases de productores, consideraron la incidencia de los costos de investigación y la distribución del beneficio social en los diferentes grupos, aunado al análisis nacional del impacto de distribución del excedente del consumidor y del productor por los ingresos en los estratos. 
Tosterud et al. (1973) citado por Norton y Davis (1981) y Kislev y Hoffman (1978) llegaron a la conclusión que se debería asumir la existencia de una curva de demanda totalmente elástica y una curva de oferta perfectamente inelástica. (Ver figura 2), independiente de si se utilizan modelos explícitos o implícitos. Este modelo ha sido adoptado por la mayoría de evaluaciones de impacto que se han realizado en Latinoamérica, ya que permite evaluar el beneficio económico en dos momentos del tiempo: uno, cuando se producía con la tecnología tradicional y un segundo cuando se realiza la adopción parcial o total de una nueva tecnología.

Figura 2. Excedentes económicos, con oferta inelástica y demanda elástica, situación inicial y final

Situación inicial

Situación final
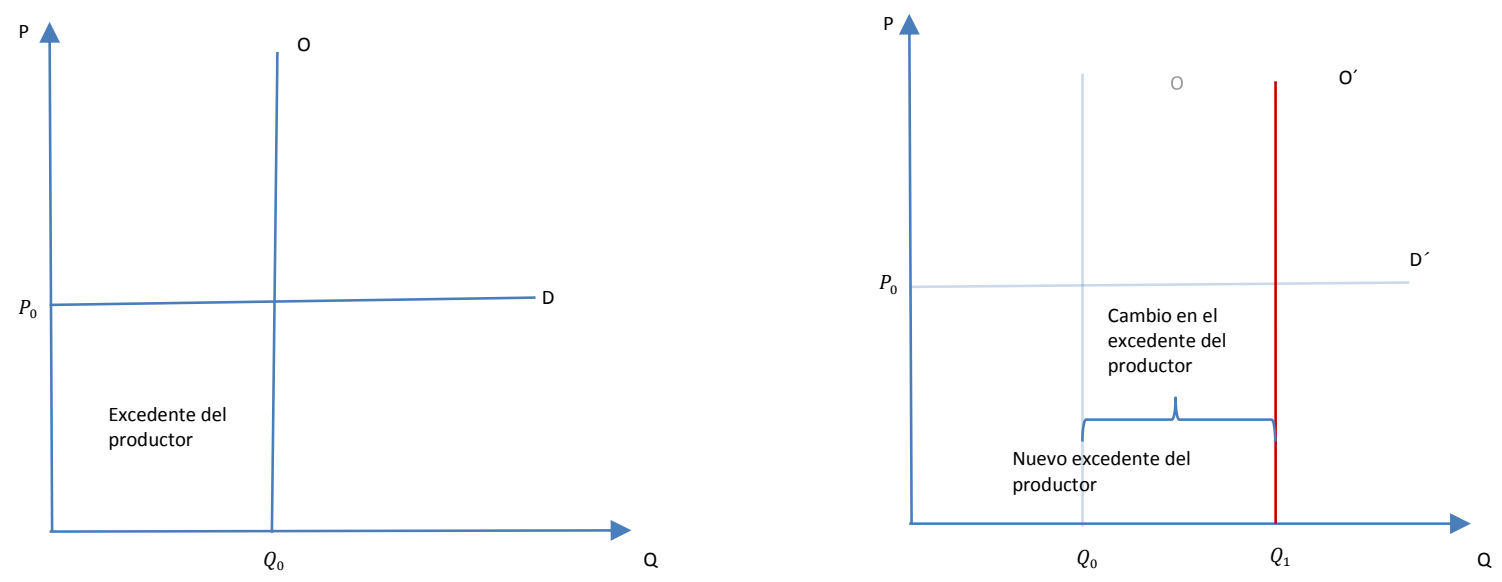

Fuente: elaboración propia

El cálculo de estos excedentes, dependería del tipo de curvas, tanto de demanda como de oferta, que se tengan, ya que se podría utilizar herramientas que van desde la geometría, como cálculo de áreas de cuadrados y triángulos hasta el cálculo integral para hallar el área bajo las curvas que corresponden a cada uno de los excedentes, del productor y consumidor. 
Los modelos que tiene como base la función de producción están dedicados, especialmente, a determinar la productividad marginal en determinado periodo de tiempo, por medio de los parámetros que definen dicha función de producción. De esta forma, el cálculo de dicha productividad está dada por la suma de los incrementos hasta determinado periodo, $t$, generados por el gasto en un peso adicional en la investigación de dicho producto agrícola en cada uno de los periodos anteriores, para terminar calculando una Tasa Interna de Retorno Marginal (TIRM), como variable proxi de rentabilidad.

Según Norton y Davis (1981) el modelo general para estimar la rentabilidad económica con base a la función de producción, está dado por:

$$
Q=\prod_{i=1}^{m} X_{i}^{\beta_{i}} \prod_{j=0}^{n} R_{t-j}^{\alpha_{t-j}} * e^{u}
$$

Dónde: Q: valor de la producción agrícola del producto, A: parámetro de cambio en un factor, $X_{i}$ es el i-ésimo insumo en la producción original, $R_{t-j}$ : gasto en investigación desde el año t hasta el j, $\beta_{\mathrm{i}}$ : coeficiente de producción del i-ésimo insumo en la producción convencional, $\alpha_{\mathrm{t}-\mathrm{j}}$ : coeficiente de producción parcial de la investigación desde el año t hasta el j y u es un término de error.

Por último, los modelos de corte social como el denominado Ambitec-social, (ver figura 3) es una herramienta que contiene 14 indicadores agrupados en cuatro aspectos de interés: empleo, renta, salud y gestión y administración, y pretenden medir la influencia de la innovación tecnológica en la agricultura a nivel social. 
Figura 3. Organograma de Ambitec

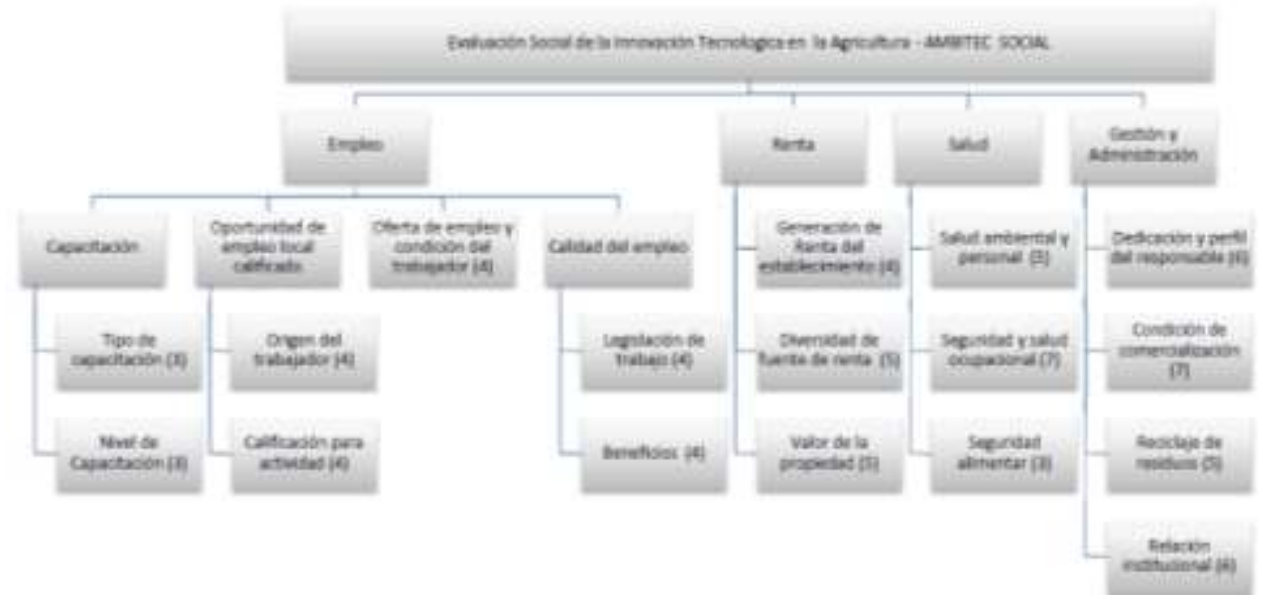

Fuente: Adaptación de Rodriguez (2008)

La utilización de Ambitec-Social se enmarca en tres etapas: 1. Proceso de levantamiento y recolección de datos generales sobre la tecnología (información sobre el alcance, la delimitación del área geográfica y el universo de agricultores que adoptan la tecnología (muestra); 2. Aplicación de entrevistas a los agricultores adoptantes seleccionados; y 3 . Análisis e interpretación de los resultados que se obtuvieron en la recolección por medio de plantillas que posee EMBRAPA.

Los indicadores obtenidos se analizan en conjunto determinando un índice de impacto social de la innovación tecnológica con una escala que varía entre -15 y +15. El cálculo de dicho índice de impacto puede ser calculado utilizando la siguiente ecuación:

$$
I I_{j}=\sum_{i=0}^{n} A_{i j} E_{i j} P_{i j}
$$

Donde: $I I_{j}$ : impacto del indicador j, $\mathrm{A}_{\mathrm{ij}}=$ coeficiente de alteración del componente i del indicador $\mathrm{j}, \mathrm{E}_{\mathrm{ij}}$ = factor de ponderación para escala de ocurrencia espacial del componente $\mathrm{i}$ del indicador $\mathrm{j}, \mathrm{P}_{\mathrm{ij}}=$ factor de ponderación para importancia del 
componente i en la composición del indicador j; $\mathrm{n}$ = número de componentes del indicador $\mathrm{j}$.

\section{HECHOS ESTILIZADOS}

El presente capitulo tiene como objetivo presentar algunos aspectos relevantes relacionados con la producción de cacao durante la última década, la revisión se centra en el análisis de algunas características del mercado nacional y mundial oferta, demanda y precios, adicional a esto se realizará una breve discusión sobre el futuro de la "cacao-cultura" colombiana y las oportunidades que esta representa para el crecimiento económico de los territorios rurales.

\subsection{Producción nacional de Cacao, Distribución departamental, Área y Rendimiento.}

Como cualquier sistema productivo en Colombia, el cacao presenta cierta distribución en el territorio, la cual se da principalmente por condiciones agroecológicas y sociales. Aunado a esto, dichas condiciones generan un nivel productivo que define la oferta de cacao a nivel nacional. A continuación se presenta la distribución y el área sembrada con cacao en Colombia, los rendimientos históricos por hectárea, y una breve comparación de los rendimientos nacionales con los de países de la región-Brasil y Ecuador-. 
Figura 3. Distribución del área sembrada con cacao en Colombia,

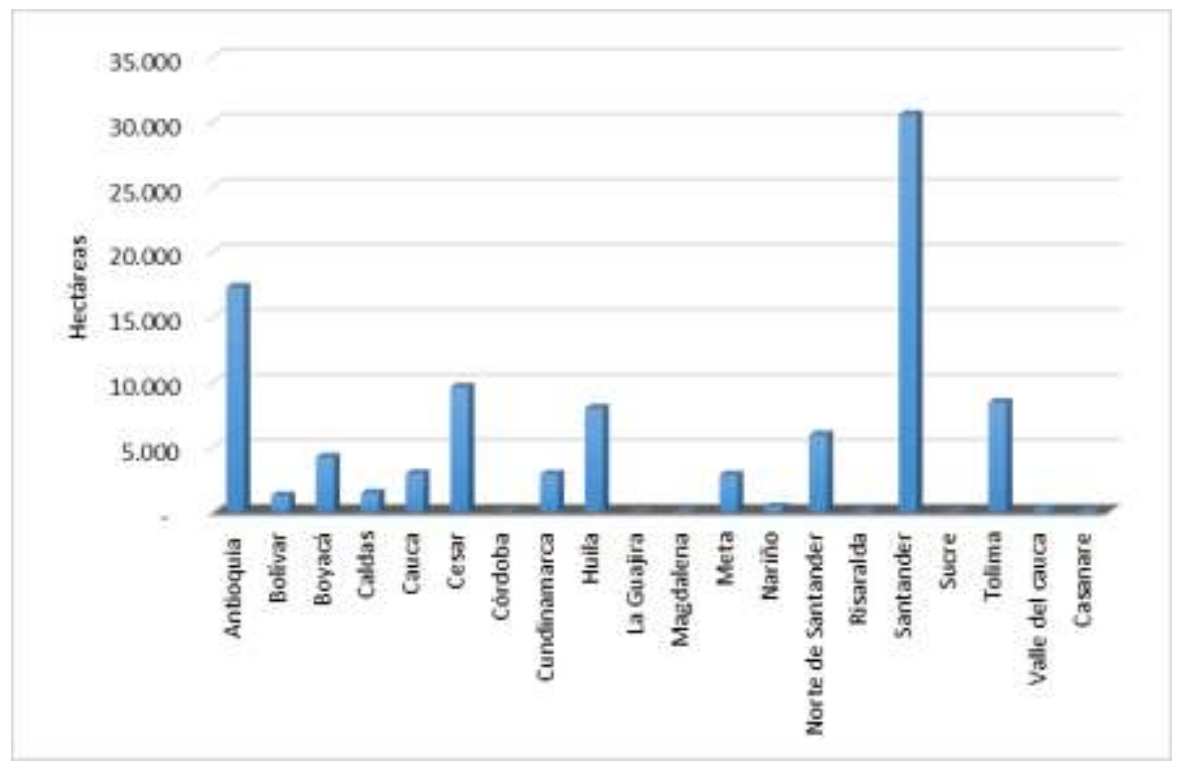

Fuente: ENA 2013

Como se evidencia en la figura 3, para el año 2013 cerca del $70 \%$ de los cultivos de cacao se concentraban principalmente en 4 departamentos, Cesar, Antioquia, Tolima y Santander, siendo este último el más importante dentro de las siembras nacionales -32\%- seguido por Antioquia -18\%-, y Cesar y Tolima cada uno con 10 $\%$ del área sembrada. Aunque para dicho periodo se reportan otros 16 departamentos con áreas sembradas, tan solo se rescata la participación de Huila y Norte de Santander, con $8 \%$ y $6 \%$ respectivamente, los restantes en conjunto suman el $16 \%$. 
Figura 4.Comportamiento del área de cacao cosechada Colombia 2003-2012.

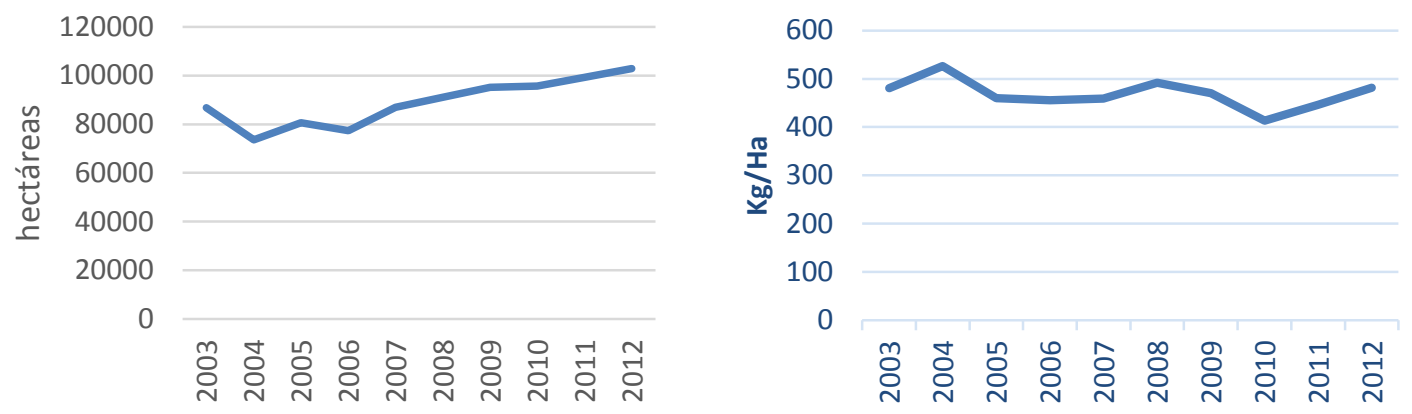

Fuente: FAO 2012

En lo referente al comportamiento del área sembrada con cacao, según el MADR, al año 2013 se superaban las ciento cincuenta mil hectáreas $-3 \%$ del total nacional- en las cuales se generó empleo para ciento dos mil personas. En cuanto al área cosechada, tal y como se observa en la gráfica 6 , se presentó una tendencia de incremento en la última década -18\% de 2003 a 2012-; también es importante destacar que durante los últimos dos años de dicho periodo, se atravesó la barrera de las cien mil hectáreas en producción, alcanzando a 2012 ciento tres mil hectáreas. Como se verá más adelante en este documento, la tendencia del área sembrada y cosechada se mantendrá al alza, e incluso podría pensarse que dadas las condiciones del mercado mundial, marcadas por el incremento de consumo especialmente de países emergentes, a un periodo de 5 años -2019- podría multiplicarse por seis el área sembrada con cacao. De acuerdo a la figura 4. Puede asegurarse que el cultivo de cacao en Colombia no ha sufrido mayores transformaciones a nivel productivo, hecho que se evidencia con el estancamiento de los rendimientos por hectárea $-480 \mathrm{~kg} / \mathrm{Ha}$-. Puede indicarse entonces, que de mantenerse tanto el rendimiento como el comportamiento del área sembrada, Colombia incrementará el agregado total de oferta, hecho que no estaría ligado necesariamente al incremento en la productividad de los cacaoteros o de los territorios.

Como herramienta de calificación para determinar qué tan "buenos" o "malos" son los rendimientos históricos del cacao en Colombia, vale presentar la comparación con rendimientos de países referentes en la región 
Figura 5. Rendimientos de cacao Brasil Colombia y Ecuador, 2003-2012

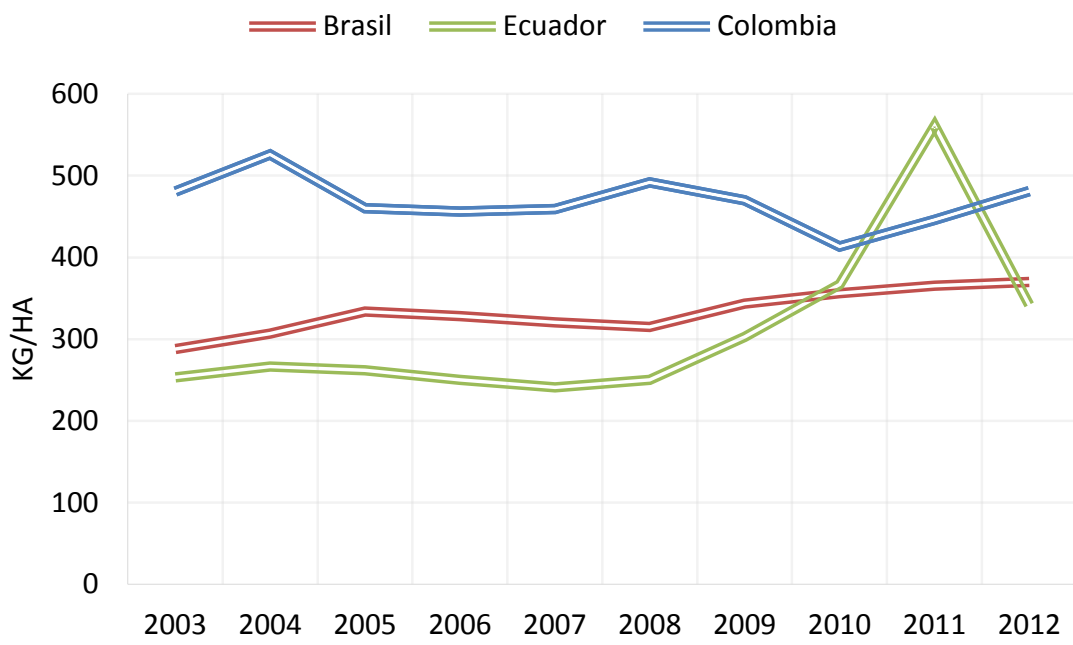

Fuente: FAO 2012

Para comenzar la comparación de rendimientos regionales de cacao, debe indicarse que tanto Brasil como Ecuador tienen mayor relevancia a nivel mundial en producción de cacao y poseen una producción cuatro o cinco veces mayor a la de Colombia. De hecho, según la FAO -2014-, Ecuador se ubica en el séptimo lugar de exportación a nivel mundial -Colombia y Brasil producen principalmente para abastecer su mercado interno-. En cuanto a rendimientos, observando las cifras, y obviando el periodo 2010-2011, en el cual Ecuador tuvo un repunte con posterior retorno a línea de tendencia, puede indicarse que los rendimientos Colombianos son ligeramente superiores a los regionales, hecho que aunque a priori podría resultar ventajoso, de ninguna manera indica o posiciona al país como referente regional en producción o en calidad. Es evidente que uno de los aspectos más importantes para incrementar la productividad de los cacaoteros es el alza en los rendimientos por hectárea, razón por la cual todos los esfuerzos a nivel de manejo agronómico se deben enfocar al mejoramiento de los cultivos y de su producción misma. 


\subsection{Las exportaciones.}

Aunque como se mencionó anteriormente, Colombia no es un país referente en exportaciones de cacao, las divisas que ingresan al país resultan relevantes si se entiende que estas impactan principalmente la economía de pequeños productores, a continuación se muestran las cifras de las exportaciones para el año 2013 desagregado por nivel de transformación-.

Figura 6. Porcentaje de participación de las exportaciones de cacao 2013

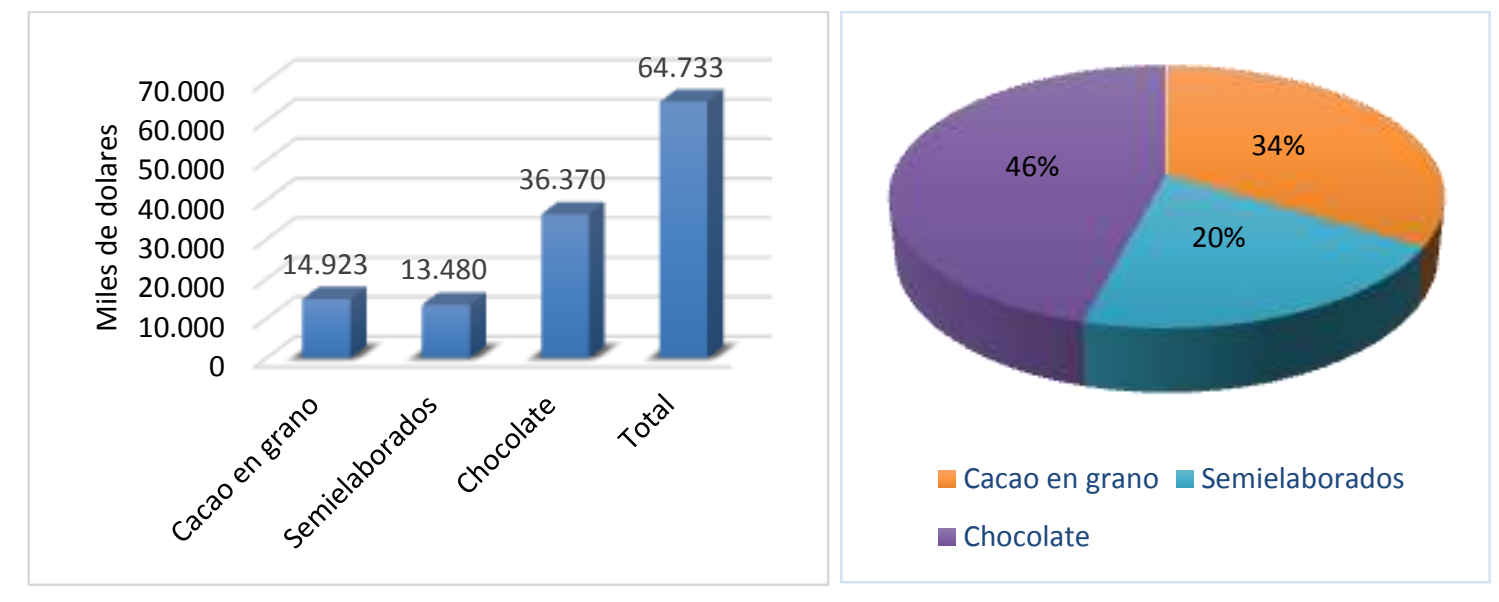

Fuente: MADR 2013

Como se observa en la figura 6 para el año 2013 Colombia reportó exportaciones de cacao o derivados, por un valor cercano a los sesenta y cuatro millones de dólares, siendo relevante el hecho que más de la mitad de ese valor se generó por concepto de ventas de chocolate, en cuanto a los valores generados por venta de cacao en grano, se alcanzaron los 15 millones de dólares, lo que representa el $23 \%$ del total, este hecho sugiere la necesidad de incrementar los procesos que generen valor agregado al cacao a fin de obtener mayor rentabilidad para la cadena y mayores divisas para el país. En cuanto a los semielaborados productos intermedios entre grano y chocolate- se reportan valores de $20 \%$ tanto en volumen exportado como en ingreso de divisas. 


\subsection{Los precios, la demanda y un posible escenario a 2019}

A continuación se revisará el comportamiento de los precios mundiales de cacao, la tendencia a futuro en temas de demanda y se realizará un breve análisis del posible escenario del mercado mundial de cacao en 2019 y las repercusiones y oportunidades que esto acarrearía para Colombia.

Como es el caso de la mayoría de los "commodities", las negociaciones de compra y venta de cacao a nivel mundial se realizan en un mercado de futuros, y es precisamente en esta dinámica de oferta y demanda en la cual se fijan los precios mundiales del producto. Aunque Colombia produce cacao para mercado nacional, cabe indicar que el precio interno del cacao se orienta según la tendencia mundial, por lo cual para el presente ejercicio es válido aportar información sobre los precios mundiales.

Figura 7. Comportamiento del precio mundial del cacao 2005-2014,

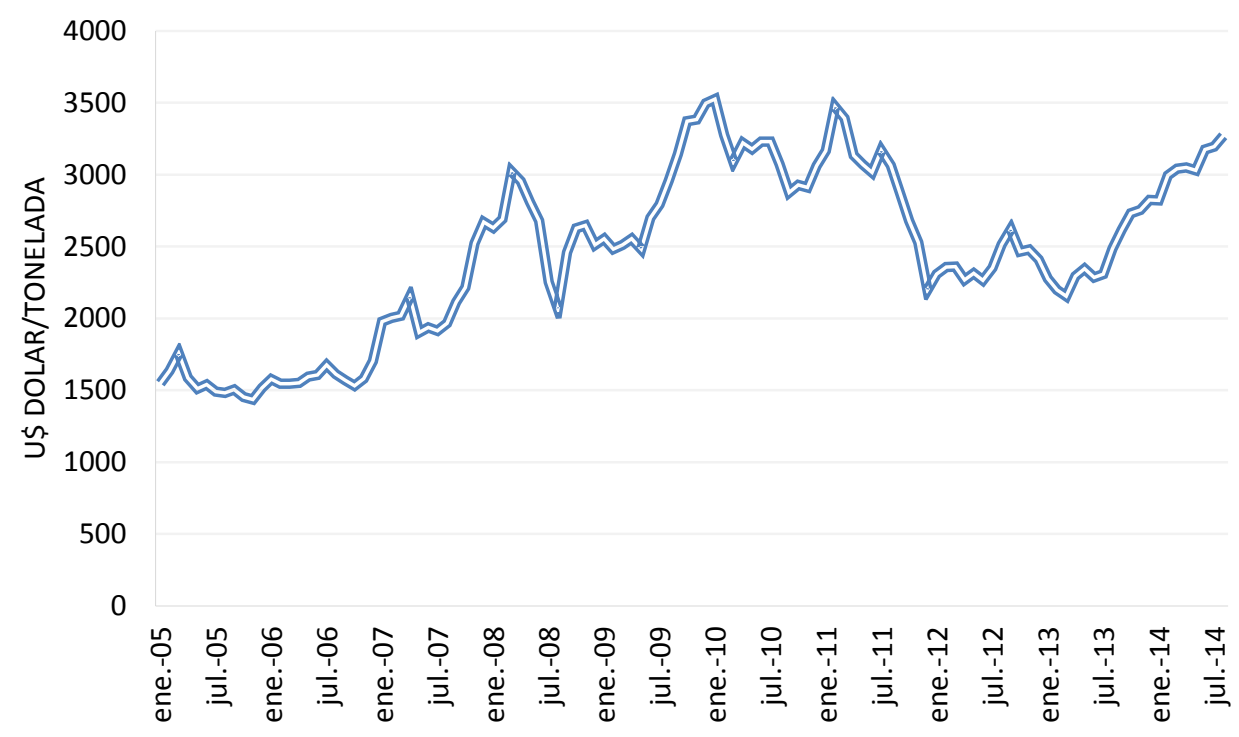

Fuente: FAO 2014 
Partiendo de la figura 7, debe indicarse, que al igual que otros alimentos y productos agrícolas, el cacao ha reportado un incremento considerado en su precio en la última década, se puede evidenciar que en 10 años el precio de mercado del cacao se ha duplicado, alcanzando valores superiores a tres mil dólares por tonelada. Este hecho sin duda constituye un elemento fundamental para el crecimiento de los territorios cacaoteros y estimula la ampliación del área sembrada en algunos países -Colombia-. Aunque para el caso puntual de Colombia es importante que se fortalezcan los precios del cacao, es necesario tener en cuenta que el ingreso real de los agricultores no depende únicamente del precio mundial, sino que debe analizarse a la par de los precios, la fluctuación del precio de las divisas, especialmente el dólar.

Según el ICCO -The International Cocoa Organization-, dada la entrada de países emergentes al mercado, especialmente China, la demanda agregada mundial se incrementará a tal nivel que hacia 2019 se podría presentar un desabastecimiento de producto y por ende una subida en los precios mundiales, es sin duda este escenario una gran oportunidad para incrementar la renta de los cacao-cultores nacionales, y es la razón por la cual desde las entidades formuladoras de política pública se ha planteado la necesidad de sembrar un millón de hectáreas adicionales de Cacao. Como principal ventaja que tendría Colombia bajo este escenario es el hecho que las producciones nacionales tan solo representan el $1 \%$ de la producción mundial, por lo cual ante el incremento de la producción con miras a exportación, el país sería un "pequeño exportador", entendido esto de otra manera, se puede afirmar que los precios mundiales resultarían inelásticos a la oferta Colombiana -no se verían afectados por la producción colombiana-, algo que sumado a una política cambiaria de devaluación, beneficiaría a los productores y a los territorios. 
Figura 8. Distribución porcentual de la producción mundial de cacao 2012

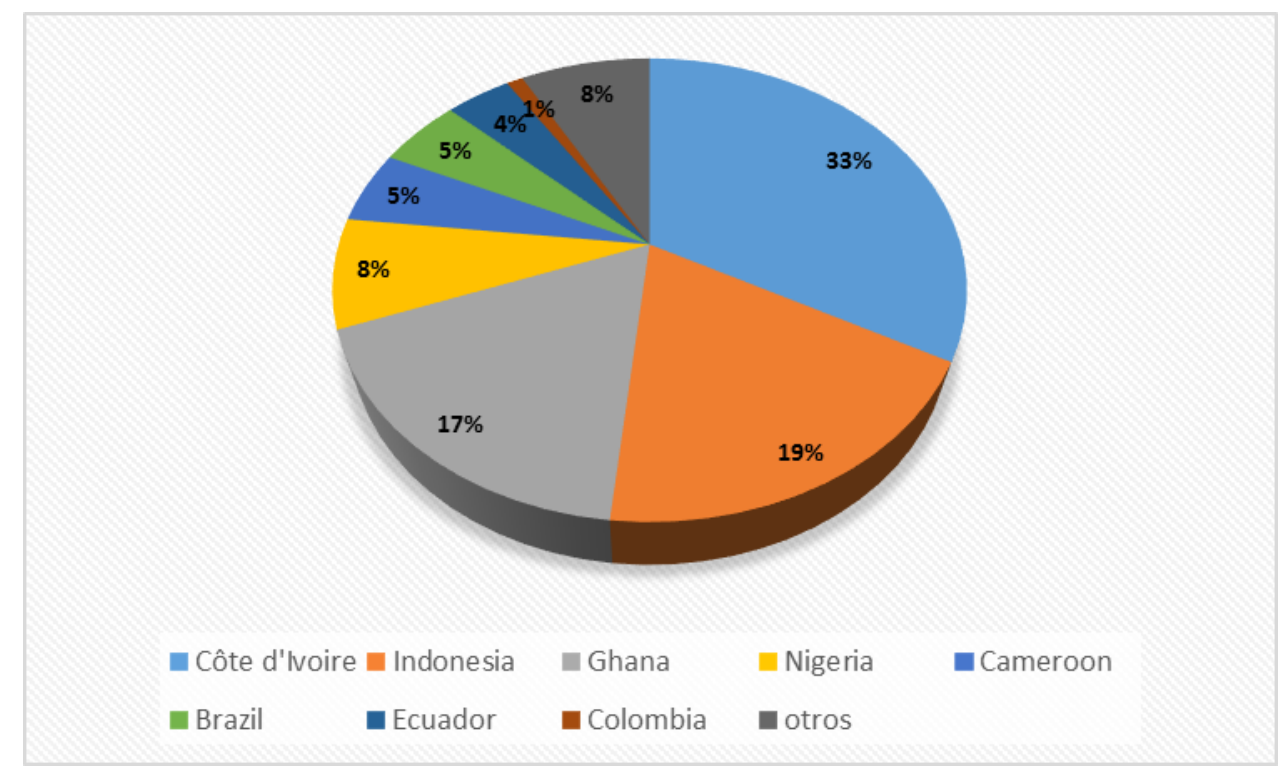

Fuente: FAO

\section{METODOLOGIA Y MODELO DE ADOPCION E IMPACTO}

Con el fin de cumplir con el objetivo de determinar la incidencia de la transferencia tecnológica en la productividad del cacao en Colombia, se estimó un modelo de probabilidad con variable dicotómica dependiente para establecer cuáles son las variables determinantes al momento de tomar la decisión de adoptar tecnologías. Para tal efecto el estudio se basó en las encuestas elaboradas en el año 2013 por Fedecacao, donde se seleccionaron 21 fincas ubicadas en la zona de Santander, Arauca y Antioquia, zonas con un alto porcentaje de producción, Lo anterior fue validado mediante un modelo econométrico "Probit",mediante el programa estadístico Stata 13.0 por medio del cual se determinó los determinantes de la adopción de tecnologías para el manejo agronómico del cultivo de cacao, se planteó una relación de variables, donde la variable dependiente se definio como el porcentaje o la probabilidad de que los agricultores 
adopten las tecnologías relacionadas con, el tipo de sistema de producción, insumos, herramientas y asistencia técnica.

Tabla No 1 Ficha técnica encuesta Fedecacao

\begin{tabular}{|l|c|}
\hline \multicolumn{2}{|c|}{ FICHA TECNICA ENCUESTA FEDECACAO } \\
\hline Número de fincas seleccionadas & 21 \\
\hline Ubicación & $\begin{array}{c}\text { Departamentos } \\
\text { productores Santander, } \\
\text { Antioquia, Arauca }\end{array}$ \\
\hline Año & 2013 \\
\hline Metodología & Modelo PROBIT \\
\hline Variable dependiente & Adopta de tecnologías \\
\hline Variables Independientes & $\begin{array}{c}\text { Sistemas de producción } \\
\text { Renovado, tradicional, } \\
\text { Material vegetal, } \\
\text { herramientas, } \\
\text { asistencia técnica, } \\
\text { genero, tenencia de la } \\
\text { tierra }\end{array}$ \\
\hline
\end{tabular}

Fuente: Construcción propia

Los resultados sobre la probabilidad que los agricultores incorporen al sistema de producción las tecnologías se pueden obtener a partir de un modelo como Probit, que utilizó McFadden (1973). De acuerdo con Madala (1996), los modelos de elección binaria asumen que los individuos se enfrentan con una elección entre dos alternativas y la elección depende de características identificables. Madala (1996); Pindyck y Rubinfeld (2001), argumentan que dichos modelos se refieren a decisiones que involucran "deseo" y "capacidad." Consecuentemente, un modelo como el expresado contendrá variables explicativas de ambos elementos o atributos. 


\section{1 .Modelo Probit}

La metodología utilizada es la propuesta por Gujarati (2002). Ahora, teniendo en cuenta que el modelo Probit surge de una función de densidad normal, distribuida con media $\mu$, y varianza $\sigma^{2}$, y se especifica cómo:

$$
\cdot f(x)=\frac{1}{\sigma \sqrt{2 \pi}} e^{-(x-u)^{2} / 2 \sigma^{2}}
$$

Y su Función de Densidad Acumulativa se expresa como,

$$
f(x)=\int_{-\infty}^{x^{0}} \frac{1}{\sigma \sqrt{2 \pi}} e^{-(x-u)^{2}} / 2 \sigma^{2}(2)
$$

Donde Xo es algún valor especificado de $X$

Para efectos del cálculo del modelo Probit se supone que la función de densidad $Z$ está distribuida normalmente con $N \sim(0,1)$ se representa a partir de la siguiente formula:

$$
f(z)=\frac{1}{\sqrt{2 \pi}} e^{-z / 2}
$$

Gujarati (2004: 587), supone también que el modelo Probit se especifica a partir de un índice de conveniencia no observable li (también conocido como variable latente), el cual está determinado por una o varias variables explicativas, por ejemplo el ingreso $X i$, de tal manera que entre mayor sea el valor índice li, mayor será la probabilidad que se dé el evento de éxito. Este índice se expresa como:

$$
I_{i}=\beta_{0}+\beta_{1} X_{i}
$$

Dada la anterior ecuación, entonces la pregunta es ¿cómo se determina la probabilidad de éxito? 
Se condiciona la variable dependiente de forma binaria $Y=1$, por ejemplo si una finca adopta tecnología entonces $Y=1$ y $Y=0$ si no lo posee.

Ahora, es razonable suponer que existen niveles críticos o umbrales en las fincas que adoptan la tecnología, de ahí que este umbral se le denomina con la letra $I_{i}^{*}$, tal que si $I_{i}$ excede a $I_{i}^{*}$, la finca adoptará la tecnología.

Pero como señala Gujarati "el umbral ${ }^{{ }^{*}}$, al igual que ${ }^{I_{i}}$, no es observable, pero si se supone que está distribuido normalmente con la misma media y varianza, es posible, no estimar los parámetros del índice sino también obtener alguna información sobre el índice no observable mismo." Con base en lo anterior (supuesto de normalidad), la probabilidad de que ${ }_{i}^{*}$ sea menor o igual que ${ }^{I_{i}}$, puede ser calculada a partir de la FDA normal estandarizada como:

$$
P_{i}=P(Y=1 / X)=P\left(I_{i}^{*} \leq I_{i}\right)=P\left(Z_{i} \leq \beta_{0}+\beta_{1} X_{i}\right)=F\left(\beta_{0}+\beta_{1} X_{i}\right)
$$

Donde $P_{i}=P(Y=1 / X)$, significa la probabilidad de que un evento ocurra, dados los valores de las variables predeterminadas y donde $\mathrm{Zi}$ es la variable estándar normal, es decir $N \sim(0,1)$. De ahí que la función del índice de conveniencia no observable se puede especificar como una función $\mathrm{F}(\mathrm{li})$ de la siguiente manera:

$$
\begin{aligned}
& F\left(I_{i}\right)=\frac{1}{\sqrt{2 \pi}} \int_{-\infty}^{I_{i}} e^{-z^{2} / 2} d z \\
& =\frac{1}{\sqrt{2 \pi}} \int_{-\infty}^{\beta_{0}+\beta_{1} X} e^{-z^{2} / 2} d z
\end{aligned}
$$

Esto mismo, puede ser representado por el área bajo la curva normal estándar de $-\infty$ a li, toda vez que $\mathrm{P}$ representa la probabilidad de la ocurrencia del evento. 


\subsection{RESULTADOS.}

Ahora bien, a través del programa estadístico Stata 13.0 se estimaron los determinantes de la probabilidad de adoptar tecnología para las submuestras de 21 fincas, que se observan en la tabla 1.

Tabla No 2. Matriz de información de las fincas seleccionadas y variables de estudio

\begin{tabular}{|c|c|c|c|c|c|c|c|c|}
\hline Nombre de la Finca & $\begin{array}{l}\text { Adopta } \\
\text { tecnología }\end{array}$ & Sistema & $\begin{array}{c}\text { Material } \\
\text { vegetal }\end{array}$ & Insumos & Herramientas & $\begin{array}{l}\text { Asistencia } \\
\text { tecnica }\end{array}$ & Genero & $\begin{array}{l}\text { Tenencia de } \\
\text { la tierra }\end{array}$ \\
\hline Finca Agua blanca & 1 & 1 & 1 & 1 & 1 & 1 & 1 & 1 \\
\hline Finca Girasol & 0 & 0 & 0 & 0 & 1 & 1 & 0 & 1 \\
\hline Finca la Paz & 0 & 0 & 0 & 1 & 0 & 0 & 0 & 0 \\
\hline Finca Palestina & 1 & 1 & 1 & 1 & 0 & 1 & 0 & 0 \\
\hline Finca Papayal & 0 & 0 & 0 & 0 & 0 & 0 & 0 & 0 \\
\hline Finca Urabá Apartado & 1 & 1 & 1 & 1 & 1 & 1 & 1 & 1 \\
\hline Finca El Recuerdo Arauca & 1 & 1 & 1 & 1 & 1 & 0 & 0 & 0 \\
\hline Finca Sama & 1 & 1 & 1 & 1 & 1 & 0 & 0 & 0 \\
\hline Finca San Jose & 1 & 1 & 1 & 1 & 1 & 0 & 0 & 0 \\
\hline Finca la Maria & 1 & 1 & 1 & 1 & 1 & 0 & 0 & 0 \\
\hline Finca Chaparral & 0 & 0 & 0 & 0 & 0 & 0 & 0 & 0 \\
\hline Finca San Vicente del chucuri 1 & 1 & 1 & 1 & 1 & 1 & 0 & 0 & 0 \\
\hline Finca San Vicente del chucuri 2 & 0 & 0 & 0 & 0 & 0 & 0 & 0 & 0 \\
\hline Finca San Vicente del chucuri 3 & 0 & 1 & 1 & 1 & 1 & 0 & 0 & 0 \\
\hline Finca villa luz & 0 & 1 & 0 & 1 & 1 & 0 & 1 & 1 \\
\hline Finca san juan & 1 & 1 & 1 & 1 & 1 & 0 & 1 & 1 \\
\hline Finca Villa esneda & 1 & 1 & 1 & 1 & 1 & 0 & 0 & 0 \\
\hline Finca a Landazuri & 0 & 0 & 0 & 1 & 0 & 0 & 0 & 0 \\
\hline Finca la perla Arauca & 1 & 1 & 1 & 1 & 0 & 0 & 0 & 0 \\
\hline Finca Granada & 0 & 0 & 0 & 1 & 0 & 0 & 0 & 0 \\
\hline Finca Yacopí & 1 & 0 & 0 & 1 & 0 & 0 & 0 & 0 \\
\hline
\end{tabular}

\section{Fuente: Datos autor}

Se estimó la adopción de tecnologías por parte de fincas las cuales producen cacao es el siguiente:

$$
\begin{gathered}
\text { adopta }=\beta_{0}+\beta_{1} \text { sistema }+\beta_{2} \text { herramientas }+\beta_{3} \text { asistencia }+\beta_{4} \text { genero }+ \\
\beta_{5} \text { tenencia }+e(7)
\end{gathered}
$$


Donde la descripción de las variables es la siguiente:

- adopta: es la variable dependiente que es la adopción de tecnología por parte de 21 fincas en Colombia. Por tanto 1 es si adopta y 0 si no lo hace.

Tabla 3. Descripción de variables Dicotómicas.

\begin{tabular}{|c|c|c|}
\hline 1 & Cultivo Renovado & $\begin{array}{l}\text { Proceso de injertación de } \\
\text { genotipos de cacao } \\
\text { seleccionados por atributos de } \\
\text { interés ( resistencia a } \\
\text { enfermedades, calidad sensorial } \\
\text { y fisicoquímica }\end{array}$ \\
\hline 0 & cultivo tradicional & $\begin{array}{l}\text { No tiene ningún proceso de } \\
\text { injertacion de nuevas plántulas } \\
\text { de cacao }\end{array}$ \\
\hline 1 & Utiliza insumos & $\begin{array}{l}\text { Utilización de fertilizantes y } \\
\text { control de plagas }\end{array}$ \\
\hline 0 & no utiliza insumos & $\begin{array}{l}\text { No utilización de fertilizantes ni } \\
\text { control biológico }\end{array}$ \\
\hline 1 & Utiliza herramientas & $\begin{array}{l}\text { Hace referencia a las } \\
\text { herramientas utilizadas en el } \\
\text { proceso de ahoyado, y } \\
\text { mantenimiento del cultivo para } \\
\text { a los genotipos del cacao, } \\
\text { resistencia a enfermedades, } \\
\text { calidad }\end{array}$ \\
\hline 0 & No utiliza herramientas & $\begin{array}{l}\text { No utiliza herramientas } \\
\text { necesarias para el proceso de } \\
\text { mantenimiento del cultivo }\end{array}$ \\
\hline 1 & Utiliza asistencia técnica & $\begin{array}{l}\text { Asesoría recibida por parte de } \\
\text { las umatas, gremios o demás } \\
\text { servicios de extensión }\end{array}$ \\
\hline 0 & no utiliza asistencia técnica & $\begin{array}{l}\text { No recibe Ningún tipo de } \\
\text { asesoría }\end{array}$ \\
\hline 1 & masculino & Genero del productor \\
\hline 0 & femenino & Genero del productor \\
\hline 1 & propietario & Tenencia de la tierra \\
\hline 0 & arrendatario & Tenencia de la tierra \\
\hline
\end{tabular}


Fuente : Datos propios

- $e$ : es el término de perturbación.

En la (tabla No 3) se observa las estimaciones realizadas por medio del modelo Probit, donde se asumió que la variable de selección tomó el valor de 1 si la finca que adopta tecnologías y 0 en caso contrario.

Los datos fueron modelados por el software estadístico Stata 13.0 los datos fueron obtenidos in situ, donde se obtuvo información con variables dicotómicas de selección discreta. Para esto se estimó e modelo Probit que permitió normalizar la muestra.

En la figura 9, se presenta que las variables como se distribuye entre 0 y 1 , alcanzan el valor minim por debajo del 0,2 y encima y de 0,8 , lo cual demuestra que los datos pueden distribuirse de manera normal.

Figura 9. Grafica de puntos del modelo Probit

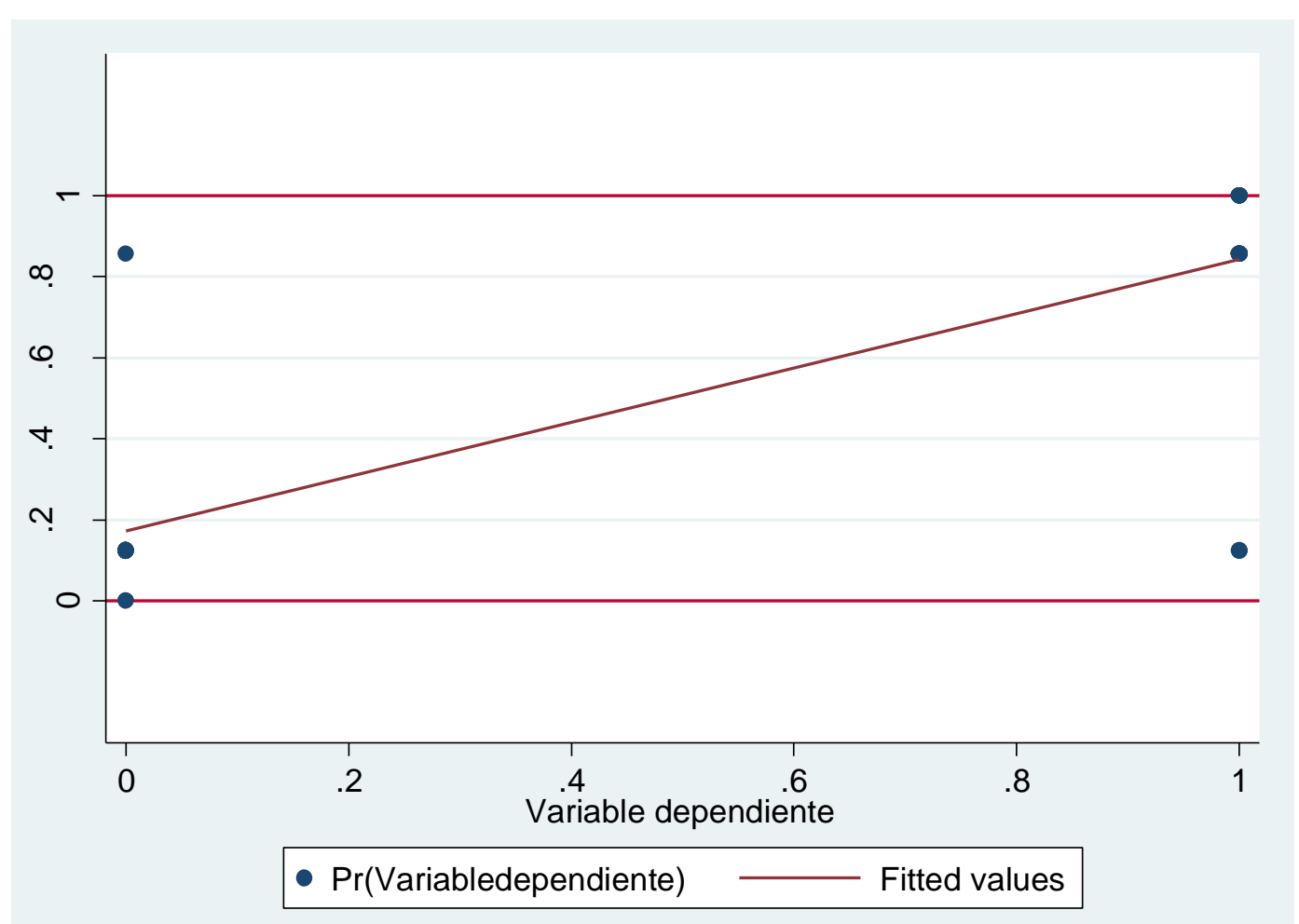

Fuente: Datos primarios, diseño propio. 
Por otro lado en la (tabla 4) la variable sistema de cultivo renovado registra una relación directamente proporcional con la probabilidad de adoptar una tecnología, es decir que a mayor sistema de cultivo renovado es la posibilidad de adoptar una tecnología. Esta corresponde al $99,7 \%$ es decir, mientras se tenga un sistema de cultivo renovado, es probable que las fincas adopten tecnologías.

\section{Tabla 4. Efectos Marginales del modelo Probit}

$$
\begin{aligned}
y & =\operatorname{Pr}(\text { Variabledependiente })(\text { predict }) \\
& =.83282742
\end{aligned}
$$

\begin{tabular}{|c|c|c|c|c|c|c|c|}
\hline variable | & $d y / d x$ & Std. Err. & z & $P>|z|$ & $95 \%$ & C.I. & $x$ \\
\hline Sistema*1 & .9976504 & 4.83174 & 0.21 & 0.836 & -8.47239 & 10.4677 & .571429 \\
\hline Herram S*| & -.8737197 & 111.94 & -0.01 & 0.994 & -220.265 & 218.517 & .52381 \\
\hline Asiste a*1 & .8737583 & 63.333 & 0.01 & 0.989 & -123.256 & 125.004 & .190476 \\
\hline Genero* & .3812088 & 209.14 & 0.00 & 0.999 & -409.529 & 410.292 & .142857 \\
\hline Tenenc a*1 & -.9990358 & 1.87421 & -0.53 & 0.594 & -4.67243 & 2.67436 & .190476 \\
\hline
\end{tabular}

(*) $d y / d x$ is for discrete change of dummy variable from 0 to 1

De igual manera, los resultados con el uso de herramientas presenta una correlación negativa, al no usar herramientas la probabilidad de no adoptar tecnologías es $87,4 \%$.

La asistencia técnica, es una de las variables que mayor probabilidad de adoptar tecnología, debido a que esta corresponde al $87,3 \%$. El género, tan solo obtuvo el $39,1 \%$. En el caso de la tenencia de la tierra, si existen más arrendatarios es probable que no se adopten tecnologías, dado que su correlación es negativa de $99,9 \%$. 
Dada la baja tecnificación del sector agropecuario colombiano y a los altos costos que afrontan los productores obliga que se adopte nuevas tecnologías para reducir dichos costos. El proceso de adopción de tecnologías permiten en gran medida que existan cultivos renovados y el uso de otros tipos de herramientas como: tijeras podadoras, navajas para injertos entre otras que faciliten la producción.

Una de las dificultades que se encontró en el desarrollo de la metodología fue la dispersión en la información en cuanto al tipo de encuesta, dado que no existe una dependencia lineal como tal entre el tipo de cultivo y los insumos utilizados para tal fin. Además se presentó una escasa coherencia y representatividad de los datos; por ende los errores estándar, resultan tener mayor dispersión por la escasa, esta información que se obtiene en datos que no se encuentran concentrados. Esto, dificulta la toma de decisiones de política económica en el agro principalmente en aspectos de competitividad y cadena de valor, aumentando el riesgo e inseguridad económica en actividades rurales rudimentarias aumentando el riesgo crediticio y de mercado.

\subsection{PRUEBAS DE SIGNIFICANCIA ESTADÍSTICA}

La prueba de significancia estadística de clasificación de variables, demuestra si el modelo como tal, se encuentra bien definido y seleccionada las variables. (La tabla 5) presenta que la clasifican de variables es del $90 \%$, lo que permite que el modelo está correctamente ajustado. 
TABLA 5. MODELO PROBIT PARA VARIABLE DEPENDIENTE

\begin{tabular}{|c|c|c|c|c|c|}
\hline Classified & I & D & $\sim D$ & I & Total \\
\hline+ & I & 10 & 1 & I & 11 \\
\hline- & I & 1 & 9 & I & 10 \\
\hline Total & I & 11 & 10 & I & 21 \\
\hline Classified & & dict & $=.4$ & & \\
\hline
\end{tabular}

\begin{tabular}{|c|c|c|}
\hline Sensitivity & $\operatorname{Pr}(+\mid D)$ & $90.91 \%$ \\
\hline specificity & $\operatorname{Pr}(-\mid \sim D)$ & $90.00 \%$ \\
\hline Positive predictive value & $\operatorname{Pr}(D \mid+)$ & $90.91 \%$ \\
\hline Negative predictive value & $\operatorname{Pr}(\sim D \mid-)$ & $90.00 \%$ \\
\hline False + rate for true $\sim \mathrm{D}$ & $\operatorname{Pr}(+\mid \sim D)$ & $10.00 \%$ \\
\hline False - rate for true $D$ & $\operatorname{Pr}(-\mid D)$ & $9.09 \%$ \\
\hline False + rate for classified + & $\operatorname{Pr}(\sim D \mid+)$ & $9.09 \%$ \\
\hline False - rate for classified - & $\operatorname{Pr}(D \mid-)$ & $10.00 \%$ \\
\hline Correctly classified & & $90.48 \%$ \\
\hline
\end{tabular}




\section{CONCLUSIONES Y RECOMENDACIONES}

El problema de la productividad y competitividad de la agro cadena del cacao se centra principalmente en los altos costos de producción dado la variación de los mismos dependiendo de la zonas agro productiva en donde se establezca.

La contribución al cambio técnico debe generar mayores niveles de producción incrementando los ingresos del pequeño y mediano productor.

A través de esta investigación se buscó determinar el nivel de adopción de los procesos de transferencia de tecnología que contribuyan a mejorar la productividad del cacao en Colombia, por consiguiente se puede concluir que los sistemas de cultivo renovado, entendiéndose este proceso como un mayor nivel de enjertación de genotipos de cacao seleccionados por atributos de interés ( resistencia a enfermedades, calidad sensorial y fisicoquímica), tienen una probabilidad del $97.7 \%$ de adopción.

Ese nivel de adopción dependerá del nivel de productividad y por consiguiente a un incremento de ingresos del pequeño y mediano pasando de $400 \mathrm{~kg} /$ has en un cultivo tradicional a $800 \mathrm{~kg} /$ has en un cultivo renovado. Mientras más sistemas de cultivo renovado persistan en las zonas identificadas, existe una probabilidad muy alta de adoptar tecnologías que disminuyan los costos y aumente la productividad por hectárea.

De igual manera el uso de herramientas presenta una correlación negativa, al no usar la cual significa al no usar herramientas la probabilidad de no adoptar tecnologías es del $87.4 \%$

La asistencia técnica, entendida esta como un proceso acompañamiento que recibe el productor por parte de las umatas, gremios o demás servicios de 
extensión para mejor aumentar el desarrollo de los cultivitos, la probabilidad de una mejora tecnológica a partir de esta variable corresponde al $87.3 \%$

El género del productor no es significativo en el momento de adoptar tecnologías, tan solo obtuvo el $39.1 \%$ al igual para el caso de la tenencia de la tierra, si existen más arrendatarios es probable que no se adopten tecnologías, dado que su correlacione es negativa de $99.9 \%$.

Se recomienda al gremio incentivar económicamente al pequeño y mediano productor para renovar o rehabilitar sus cultivos dado la política del plan Nacional de Desarrollo Cacaotero 2012 - 2021 el cual busca aumentar 150.000 has y renovar 80.000 plantaciones para producir 285.6000 toneladas.

Los centros de investigación agropecuaria deben generar y desarrollar tecnologías y contribuyan a las necesidades reales del pequeño y mediano productor, ya que existe una desarticulación entre la investigación Biofísica y la investigación Socioeconómica. 


\section{REFERENCIAS BIBLIOGRAFICAS}

Alvarado, J. 2010. El análisis post-optimal en programación lineal aplicada a la agricultura. Reflexiones. Universidad de Costa Rica.

Andoseh, S., et al. 2013. The case for a real options approach to ex-ante costbenefit analyses of agricultural research projects. Food Policy. Recuperado de http://dx.doi.org/10.1016/..foodpol.2013.09.016

Araji, A., et al. 1978. Returns to agricultural research and extension programs: An ex-ante approach. American Journal of Agricultural Economics. Vol 60, № 5 . USA, (Dec., $\quad$ 1978). Recuperado de http://www.jstor.org/discover/10.2307/1240129?uid=2\&uid=4\&sid=2110434594261 $\underline{7}$

Artachinda, O. y Akratanakkul, P. 2010. Priority Setting for Agricultural Biotechnology Research in Thailand. ARE Working Paper No. 2553/3. Department of Agricultural and Resource Economics, Faculty of Economics, Kasetsart University, Bangkok. Recuperado de ftp://ftp.repec.org/opt/ReDIF/RePEc/kau/wpaper/are201003.pdf

Arriaza, M. y Nekhay, O. 2010. Evaluación social multicriterio del territorio agrícola: el caso del olivar de baja producción. Revista españolas de estudios agrosociales y pesqueros. $\quad \mathrm{N}^{\circ} 226$ Recuperado de http://www.magrama.gob.es/ministerio/pags/biblioteca/revistas/pdf REEAP\%5Cre eap 226 completa.pdf

Behzadiana, M. et al. 2010. PROMETHEE: A comprehensive literature review on methodologies and applications. European Journal of Operational Research. Volume 200, Issue 1, January. Recuperado de http://ac.elscdn.com/S0377221709000071/1-s2.0-S0377221709000071-

main.pdf? tid=7db9eba4-0eb7-11e4-895900000aab0f27\&acdnat=1405714378 8b47098fb27e0e8e60d2bf1ab2aaaee4

CEPEP. 2007. Apuntes sobre Evaluación social de proyectos. México. Recuperado de http://www.cepep.gob.mx/libro.html 
Diaz, F. y Sain, G. 2007. "Evaluación de impactos potenciales de proyectos financiados por FONTAGRO -IICA. Recuperado de http://www.fontagro.org/sites/default/files/evaluacion impactos $2 \mathrm{y} 3$ convocatoria. $\underline{\mathrm{pdf}}$

Embrapa. Informação Tecnológica. p.85-101. Disponible en: http://bs.sede.embrapa.br/2009/metodologiareferenciaavalimpactoembrapa.pdf

Evenson, R. 1987. Productivity Decomposition Methods for Evaluation of Agricultural Research Systems Impact. New Haven. Embrapa/Economic Growth Center. Yale University.

Godet, M. 2007. Prospectiva Estratégica: problemas y métodos. Instituto Europeo de Prospectiva y Estrategia. Cuadernos de LIPSOR, Paris.

Griliches, Z. 1958. Research costs and social returns: Hybrid cron and related innovations. Journal of Political Economics. Vol. 66. Recuperado de http://www.jstor.org/discover/10.2307/1826669?uid=2\&uid=4\&sid=2110434594261 $\underline{7}$

Gutiérrez-Guzmán, N., et al. 2012. Priorización de factores críticos para implantar buenas prácticas agrícolas en pequeños productores. Cuadernos de desarrollo rural, 9 (69), 221-237. Recuperado de file:///C:/Users/sroa/Downloads/4374-157281-PB\%20(1).pdf

Hazell, P. \& Haddad, L. 2001. La investigación agrícola y la reducción de la pobreza. Documento de Discusión No. 34 de Visión 2020. IFPRI. Recuperado de http://ageconsearch.umn.edu/bitstream/16341/1/br010070.pdf

Kaimowitz; Et al 2012 Métodos de priorización en la investigación agropecuaria

Khush, G. \& Toenniessen, G. 1991. Rice Biotechnology. International Rice Research Institute. Biotechnology in Agriculture. №. 6.

Kislev, Y. \& Hoffman, M. 1978. Research and productivity in wheat in Israel. Journal of Development Studies. Vol. 14.

Leholm, A. et al. 1980. A Methodology for Measuring Potential Benefits from Drought-Oriented Research in Nebraska. Evaluation of Agricultural Research, Proceedings of a Workshop. Miscellaneous Publication 8, University of Minnesota, Agricultural Experiment Station. Minneapolis. (May 12-13, 1980). Recuperado de http://digitalcommons.unl.edu/cgi/viewcontent.cgi?article=1121\&context=ageconfac pub 
Medina, H. 1991. Métodos y modelos para priorizar la investigación agropecuaria. Serie publicaciones misceláneas. IICA. San José, Costa Rica. Recuperado de http://orton.catie.ac.cr/repdoc/A9407E/A9407E.PDF

Mortazavi, et al. 2011. The application of Multi Attribute Decision Methods (MADM) on prioritizing Iranian fisheries research projects. Iranian Journal of Fisheries Sciences. 10(1) 47-66. Recuperado de http://www.jifro.ir/files/site1/user files eb12be/admin-A-10-1-59-1882af6.pdf

Mudahar, S, et al. 1998. Transforming Agricultural Research Systems in Traditional Economies: The Case of Russia. World Bank Discussion Paper No. 396. Banco Mundial, Washington. Recuperado de http://wwwwds.worldbank.org/external/default/WDSContentServer/WDSP/IB/2000/02/24/0000 09265 3980928162812/Rendered/PDF/multi page.pdf

Norton, G. \& Davis, J. 1981. Evaluating Returns to Agricultural Research: A Review. American Journal of Agricultural Economics. Vol. 63, No. 4 (Nov., 1981). Recuperado de http://www.jstor.org/discover/10.2307/1241211?uid=2\&uid=4\&sid=2110434594261 $\underline{7}$

Norton, G., et al. 1987. Potential benefits for agricultural research and extension in Peru. American Journal of Agricultural Economics. Vol. 69. Recuperado de http://www.jstor.org/discover/10.2307/1242274?uid=2\&uid=4\&sid=2110434594261 $\underline{7}$

Norton, G. 1989. Methods to assist with agricultural research priority setting. Virginia Polytechnic Institute and State University. Virginia.

Peña, D. 2002. Análisis de datos multivariados. Mac Graw Hill. Madrid. Recuperado de http://civil2011.bligoo.cl/media/users/15/791368/files/138227/An lisis de Datos M ultivariantes - Daniel Pe a.pdf

Ramalho de Castro, J. \& Schuh. G. 1974. An economic model for establishing priorities for agricultural research and a test for the Brazilian economy. Brasilia.

Rodrigues, G. 2008. Avaliação dos Impactos de sociais de tecnologias agropecuárias en Avaliação dos Impactos de tecnologias geradas pela Embrapa: Metodologia de referência. Brasília, DF. Recuperado de http://bs.sede.embrapa.br/2013/metodologiareferenciaavalimpactoembrapa.pdf 
Russell, D. 1975. Resourse allocation in agricultural research using socioeconomic evaluation and mathematical models. Canadian Journal of Agricultural Economics. Vol 23, №2. (Jul., 1975).

Saaty, T. \& Vargas, L. 2001. Models, methods, concepts \& applications of the Hierarchy process. Kluwer academic. Massachusetts.

Schultz, T. 1953. The economic organization of agriculture. New York. McGraw Hill. Recuperado de http://ageconsearch.umn.edu/bitstream/8823/1/21020141.pdf

Scobie, G. \& Posada, R. 1978. The impact of technical change of income distribution: the case of rice in Colombia. American Journal of Agricultural Economics. Vol. 60.6 Recuperado de http://impact.cgiar.org/sites/default/files/pdf/146.pdf

Sierra, J.C., et al. 2013. Viabilidad financiera para la producción y exportación de gulupa (Passiflora edulis Sims) hacia el mercado español. Revista Corpoica, ciencia y tecnología agropecuaria. Vol. 14. Bogotá.

Sierra, J. 2003. La propiedad y el control de las decisiones de internacionalización de las empresas. Cuadernos de Administración. Vol 16. Num 26. Pontificia Universidad Javeriana. Recuperado de http://www.redalyc.org/pdf/205/20502606.pdf

Tosterud, R., et al. 1973. Benefit-cost evaluation of research relating to the development of Selkirk wheat and target rapeseed in Proceedings of 1971 Symposia on agricultural research. University of Manitoba. Dept. of Agricultural Economics and Farm Management. Vol 1. Canada. 